\title{
Probabilistic approach to assessing and monitoring settlements caused by tunneling
}

\author{
Authors: Carles Camós ${ }^{1 *}$, Olga Špačková ${ }^{2}$, Daniel Straub² and Climent Molins ${ }^{3}$.
}

\begin{abstract}
Affiliations:
${ }^{1}$ DB Netz AG. Richelstr. 3, 80634 Munich (Germany) (The present paper was developed in ${ }^{2}$ and ${ }^{3}$ )

${ }^{2}$ Engineering Risk Analysis Group, Technische Universität München. Theresienstr. 90, 80333 Munich (Germany)

${ }^{3}$ Universitat Politècnica de Catalunya. Jordi Girona 1-3, C1-206, 08034 Barcelona (Spain)
\end{abstract}

*Corresponding author: carles.camos-andreu@deutschebahn.com

\begin{abstract}
Tunnel construction commonly causes deformations of the surrounding ground, which can endanger buildings and other structures located in the vicinity of the tunnel. The prediction of these deformations and damages to buildings is difficult, due to limited knowledge of geotechnical conditions and due to uncertainty in predicting the response of the structures to the settlements. This motivates the development of a probabilistic model for the prediction of tunneling-induced damage to buildings. We propose such a model, based on the classical Gaussian profiles for the approximation of the subsidence trough and the equivalent beam method for modeling the response of the building walls. In practice, settlements are commonly monitored through deformation measurements. To account for this, we present a Bayesian method for updating the predicted settlements when measurements are available. Finally, we show how maximum allowable settlements, which are used as threshold values for monitoring of the construction process, can be determined based on reliability-based criteria in combination with measurements. The proposed methodology is applied to a group of masonry buildings affected by the construction of the L9 metro line tunnel in Barcelona.
\end{abstract}

Keywords: Tunneling, allowable settlement, building damage, equivalent beam, reliability, Bayesian updating.

\section{Introduction}

Tunneling construction leads to ground subsidence, which can endanger buildings and infrastructure in the vicinity of the tunnel. Settlements caused by tunneling can be modeled using Gaussian profiles (Peck, 1969; Attewell and Woodman, 1982; Attewell et al., 1986). This simple model describes the geotechnical conditions by two parameters: the volume loss $V_{L}$ and the trough width parameter $K$ of the settlement trough. Once the settlement profile is determined, the resulting damages in buildings are commonly modeled by applying the equivalent beam method (Burland and Wroth, 1974; Boscardin and Cording, 1989). This method determines the maximum tensile strain in a particular building wall by modeling it as a linear elastic beam 
subjected to a given deflection ratio. This strain value is then compared with limiting strain values, which define different categories of damage to buildings, from negligible to very severe.

Prediction of damages is important as a basis for tunnel design, selection of the construction technology and for setting allowable limits on settlements. These allowable values of settlement are used in the construction phase for control purposes: if the measured settlement exceeds the allowable values, the construction is stopped and/or additional safety measures are taken. However, the prediction of damages to buildings caused by tunnel construction entails uncertainty due to (a) our limited knowledge of geotechnical conditions and simplified geotechnical models and (b) uncertainty on the response of structures subjected to differential settlements. This motivates the use of probabilistic approaches for the prediction of settlements and for determining allowable settlement values (Gong et al., 2014).

First attempts to the determination of allowable settlements for buildings were made by Skempton and McDonald (1956), who defined allowable settlements according to evidence of existing data surveys of buildings. Settlement limits were determined for cases of panels in frame buildings and walls in load-bearing wall buildings. At present, the limits on allowable settlements are usually determined on a deterministic basis without consideration of uncertainty in the ground and building parameters. For example, Yoo and Kim (2003) proposed an approach for the determination of the maximum allowable volume loss in the construction of the Metro Subway Line 2 in Daegu (South Korea). The approach was based on a Gaussian profile of the settlement trough and the equivalent beam model. An iteration procedure was applied to identify the value of volume loss (and hence the allowable value of settlement) that would lead to damages below an acceptable level.

We propose a probabilistic model for the estimation of building damage due to tunneling, which is based on the Gaussian profile for the approximation of the subsidence trough and the equivalent beam method for modeling the response of the building walls (Sec. 2). The proposed methodology allows taking into account the uncertainties associated with the main model parameters, namely the volume loss $V_{L}$, the trough width parameter of the settlement profile $K$, the ratio of the Young's modulus to the shear modulus of the building and the model errors.

Based on the probabilistic model, we propose a novel approach for determining the allowable settlement on a reliability basis (Sec. 3). We demonstrate how the probabilistic model can be updated based on measurements using Bayesian analysis. This allows the computation of the conditional probability of damages given settlement measurements. The allowable settlement is then defined as the maximum measured settlement, for which the conditional probability of damage to a building wall is acceptably low. The approach was first introduced in Camós et al. (2013), here it is extended to account for the fact that the settlement depends on the actual phase of construction, i.e. on the distance of the tunnel heading from the point of measurement.

The proposed methodology is applied to a case study of masonry buildings affected by the construction of the L9 metro line in Barcelona (Sec. 4). A parametric study is included to analyze the influence of the different model parameters on the estimation of allowable settlements.

\section{Probabilistic model of building damage due to tunneling}

A typical tunneling situation is depicted in Figure 1 and Figure 2, with a building wall of length $l_{\text {build }}$, with its reference point $\hat{A}$ located at a distance $d_{\text {orig }}$ from the origin of coordinates and 
aligned $\theta$ degrees with respect to the tunnel transverse plane (Camós and Molins, 2015). The depth of the tunnel axis and the tunnel diameter are $z_{0}$ and $d$ respectively. Note that the analysis of an entire building should include all exterior walls. However, from now on we will refer to building damage as the damage occurring only in a particular wall, without considering the contribution of the other walls. Alignments counterclockwise with respect to the $x$-axis are positive $(\theta>0)$. The $y$ axis follows the tunnel longitudinal axis, whereas the $x$ axis corresponds to a transverse plane to the tunnel. The origin of coordinates is set to the intersection of the longitudinal axes of the tunnel and of the building wall. This implies that the coordinate system is a different one for each considered building (wall). The tunnel face is located at coordinate $y_{s}$ and it advances towards $y=-\infty$, following the criteria set by Attewell et al. (1986)

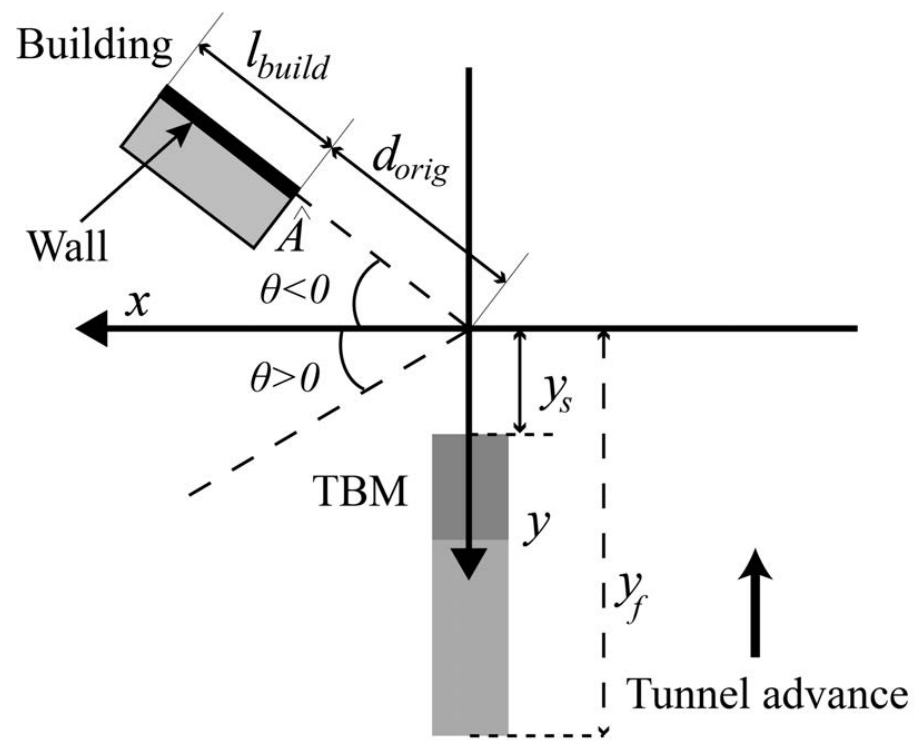

Figure 1. Tunnel and building positions (from Camós and Molins, 2015).

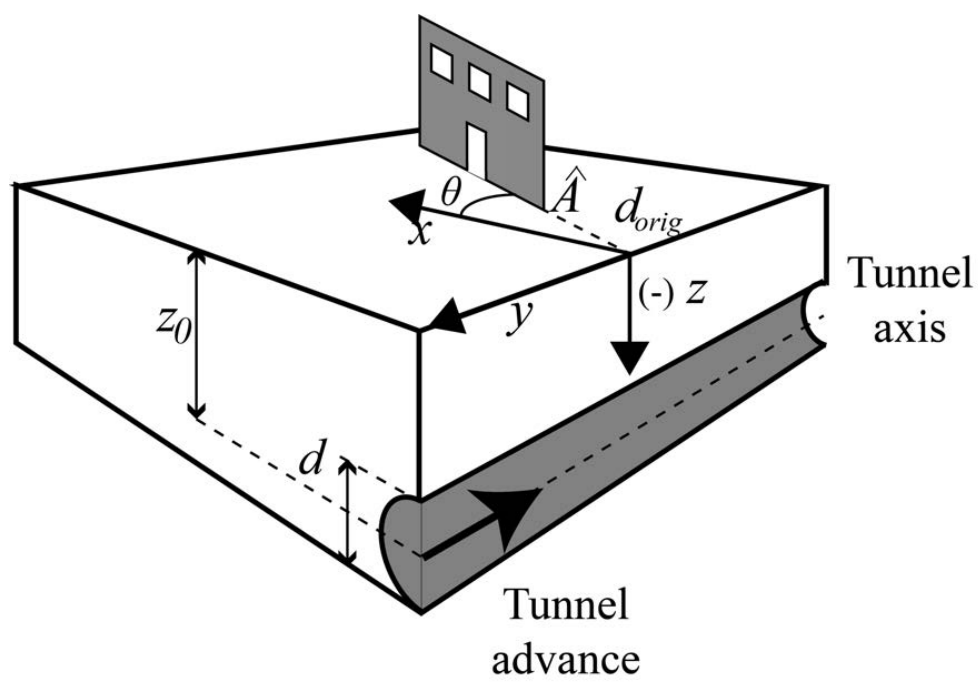

Figure 2. 3D view of tunnel and building wall positions 


\subsection{Modeling of ground settlement - Gaussian profiles}

Gaussian profiles of tunneling-induced settlements consist of a Gaussian probability density function describing the shape of settlements in the transverse direction ( $x$-axis) and a Gaussian cumulative distribution function describing it in the longitudinal direction ( $y$-axis). An example of a Gaussian profile is shown in Figure 3.

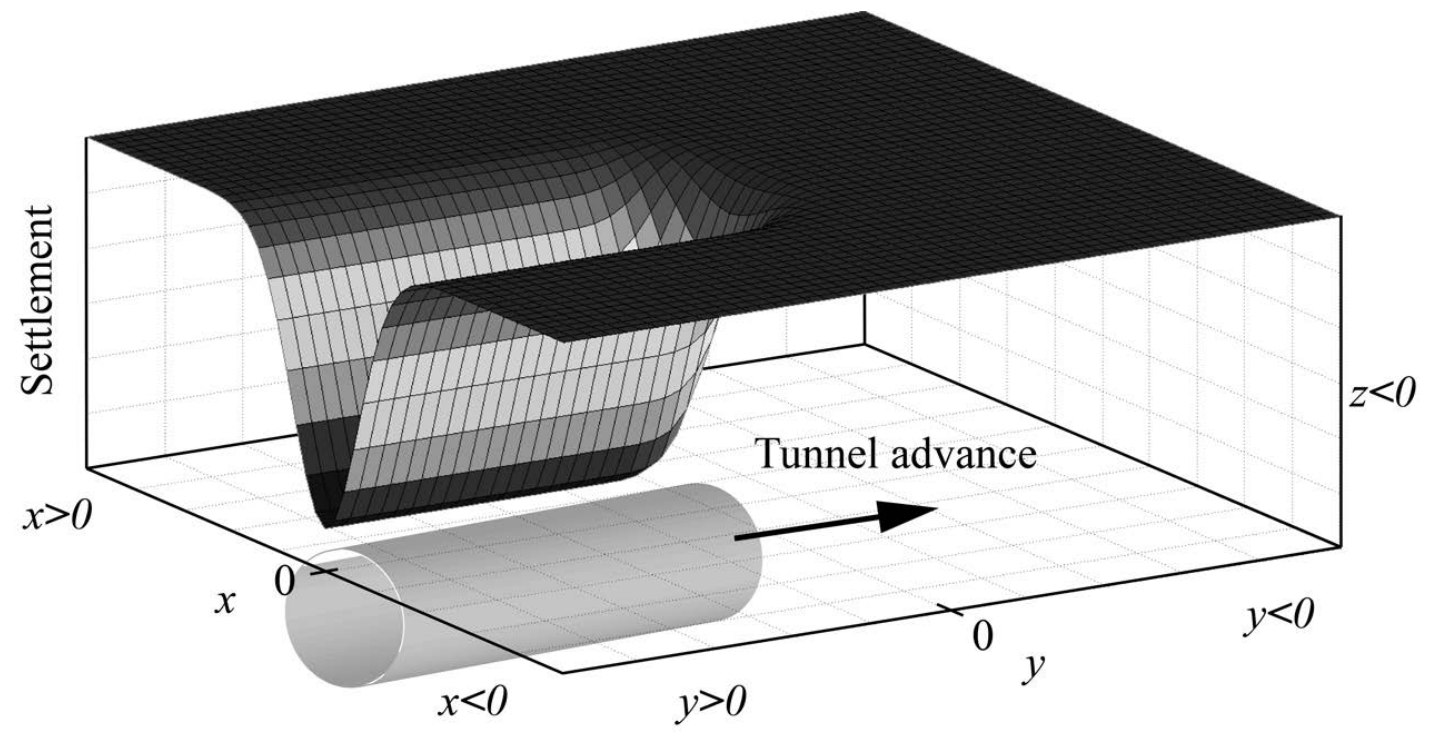

Figure 3. Settlement trough produced by tunnel excavation in the transverse $(x)$ and longitudinal $(y)$ directions. The origin of the coordinate system is set relative to the position of the analyzed building wall.

The settlement in $[\mathrm{mm}]$ at a certain position with coordinates $x, y, z$ in $[\mathrm{m}]$ is calculated by (Peck, 1969; Attewell and Woodman, 1982; O'Reilly and New, 1982):

$S\left(x, y, z, d, y_{s}, y_{0}, y_{f}, z_{0}, V_{L}, K_{x}, K_{y}\right)=-1000 \cdot S_{\max } \cdot \exp \left[-\frac{x^{2}}{2 \cdot K_{x}^{2} \cdot\left(z_{0}-z\right)^{2}}\right]$.

$\cdot\left[\Phi\left(\frac{y-\left(y_{s}+y_{0}\right)}{K_{y} \cdot\left(z_{0}-z\right)}\right)-\Phi\left(\frac{y-y_{f}}{K_{y} \cdot\left(z_{0}-z\right)}\right)\right]$

where $S_{\max }$ is the absolute value of maximum settlement far behind the tunnel face, where the deformations are fully developed. It is calculated as:

$S_{\text {max }}=\frac{V_{L} \cdot \pi \cdot d^{2}}{\sqrt{2 \pi} \cdot K_{x} \cdot\left(z_{0}-z\right) \cdot 4}$

$d$ and $z_{0}$ are given in meters. $z_{0}$ is a positive magnitude. $y_{s}$ represents the position of the tunnel face as shown in Figure 1. $y_{0}$ is the horizontal shift of the longitudinal settlement profile with respect to the tunnel face. $y_{f}$ is the distance of the tunnel portal. In the remainder of this paper we consider a situation when the tunnel heading is far from the tunnel portal, i.e. we set $y_{f}=+\infty . \Phi($.$) is the standard normal cumulative distribution function. Note that term of \Phi($. in Eq. (1) that contains $y_{f}$ becomes 0 if $y_{f}=+\infty . V_{L}$ is the volume ground loss per unit, $K_{x}$ and $K_{y}$ are non-dimensional trough width parameters describing the Gaussian settlement profiles in the transverse and longitudinal direction. $K_{x}$ and $K_{y}$ depend on the type of soil: high values of the parameter indicate flat/broad settlement curves (stiff or soft silty clays), low values indicate 
sharp/narrow settlement curves (granular soils). In this paper we limit ourselves to the case of $K_{x}=K_{y}=K$, as it is often assumed in tunneling design (Attewell et al., 1986). The product $K \cdot z_{0}$ determines the location of the inflection points $i_{x}=i_{y}=i$ of the Gaussian profiles. $V_{L}$ and $K$ are modeled as random variables (RVs). Note that settlements $S$ in Eq. (1) are considered to be negative along the $z$-axis. It is important to keep this sign convention for the correct application of related equations of ground horizontal displacements and strain (see Annex B). However, references to settlement magnitudes will be expressed in absolute values throughout the paper.

It is usually assumed that the settlement above the tunnel face corresponds to half the maximum settlement $S_{\max }$, which occurs at a distance far behind from the tunnel face. However, it has been shown that this value can be lower, depending on the type of ground and the construction technology (Nomoto et al. 1995, Fargnoli et al. 2013). Field observations for shield tunneling in sands or silts indicate that a major part of the settlements is related to the tail void, since tunnel pressure tends to restrict ground movements on the heading. Therefore, the surface settlement above the tunnel face is expected to be lower than $0.5 \cdot S_{\max }$ for these soil types. To address this, the parameter $y_{0}$ is introduced in Eq. (1) to model the shift of the longitudinal Gaussian settlement profile with respect to the tunnel face - see Figure 4. The horizontal shift $y_{0}$ is given by (Camós and Molins, 2015):

$y_{0}=-\Phi^{-1}(\delta) \cdot K \cdot z_{0}$

where $\delta$ is the ratio between the surface settlement above the tunnel face and the maximal settlement $S_{\max }$ at infinite distance of the face:

$\delta=\frac{\left|S\left(x=z=0, y=y_{s}\right)\right|}{|S(x=0, y=+\infty, z=0)|}=\frac{\left|S\left(x=z=0, y=y_{s}\right)\right|}{S_{\max }}$

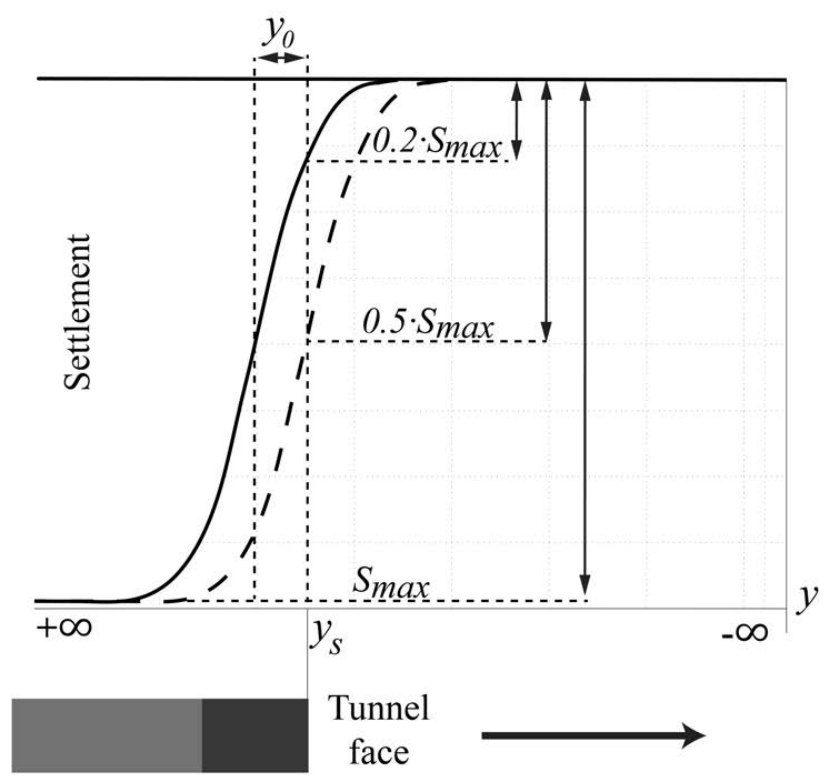

Figure 4. Longitudinal settlement profile for $\delta=0.2$ (solid line) and for $\delta=0.5$ (dashed line) (from Camós and Molins, 2015). 


\subsection{Modeling of the building response: the equivalent beam method}

The response of the building to the settlement is modeled using the equivalent beam method, which represents a building wall by means of a weightless linear elastic rectangular beam. The extreme tensile strains in the beam are calculated for a given shape of the deflection. The distribution of strains in the beam depends on the mode of deformation. Therefore, extreme modes of bending and shear are analyzed separately. The extreme fiber strains in bending, $\varepsilon_{b r}$, and in shear, $\varepsilon_{d r}$, are given by the following equations:

$\varepsilon_{b r}\left(V_{L}, K, \frac{E}{G}\right)=\left(\varepsilon_{b \max }+\varepsilon_{h}\right) \cdot E_{\varepsilon_{b r}}$

$\varepsilon_{d r}\left(V_{L}, K, \frac{E}{G}\right)=\left[\varepsilon_{h}\left(1-\frac{E}{4 G}\right)+\sqrt{\frac{\varepsilon_{h}^{2}}{16}\left(\frac{E}{G}\right)^{2}+\varepsilon_{d \max }^{2}}\right] \cdot E_{\varepsilon_{d r}}$

where $\frac{E}{G}$ is the ratio between the Young's modulus and the shear modulus of the building material; $\frac{E}{G}$ is modeled as a RV. $E_{\varepsilon_{b r}}$ and $E_{\varepsilon_{d r}}$ are multiplicative model errors, they are lognormal RVs with mean value equal to 1 .

$\varepsilon_{\text {bmax }}$ and $\varepsilon_{d \max }$ are the maximum bending and shear strains due to deflection. Their calculation is described in Annex A. $\varepsilon_{h}$ is the resultant horizontal strain in the ground surface along the base of the beam. It is calculated based on the field of ground horizontal displacements as (Camós and Molins, 2015):

$\varepsilon_{h}\left(x, y, z, V_{L}, K\right) \equiv \cos ^{2} \theta \cdot \varepsilon_{h, x x}+\sin ^{2} \theta \cdot \varepsilon_{h, y y}+2 \cdot \cos \theta \sin \theta \cdot \varepsilon_{h, x y}$

where $\theta$ is the angle between the axes of the wall and of the tunnel, as shown in Figure 1 and $\varepsilon_{h, x x}, \varepsilon_{h, y y}$ and $\varepsilon_{h, x y}$ are the fields of strain in the ground that are calculated as shown in Annex B. Note that Eq. (7) is an extension of the typically used model that assumes that one of the building axes is perpendicular to the tunnel axis. The proposed extension allows modeling an arbitrary position of the building wall with respect to the tunnel. If the wall is perpendicular to the tunnel axis (i.e. $\theta=0$ ), Eq. (7) reduces to $\varepsilon_{h}=\varepsilon_{h, x x}$. If the wall is aligned with the tunnel longitudinal axis (i.e. $\theta=90$ ), Eq. (7) reduces to $\varepsilon_{h}=\varepsilon_{h, y y}$.

The calculation of extreme fiber strains according to Eqs. (5)-(6) is performed separately for the zone of the building undergoing sagging deflection and for the zones undergoing hogging deflection, as explained in Annex A. The building can be divided into up to 3 zones: one sagging zone and two hogging zones (case $d$ in Annex A). For each zone, the maximum strains in bending and in shear are calculated. The damage on the buildings is then determined depending on the maximum strain $\varepsilon_{\max }$ :

$\varepsilon_{\max }=\max \left[\varepsilon_{b r}^{s a g}, \varepsilon_{d r}^{s a g}, \varepsilon_{b r}^{h o g, 1}, \varepsilon_{d r}^{h o g, 1}, \varepsilon_{b r}^{h o g, 2}, \varepsilon_{d r}^{h o g, 2}\right]$

where $\varepsilon_{b r}^{s a g}, \varepsilon_{b r}^{\text {hog,1 }}$ and $\varepsilon_{b r}^{\text {hog,2 }}$ are the maximum bending strains in sagging and hogging in the three zones, obtained with Eq. (5), and $\varepsilon_{d r}^{s a g}, \varepsilon_{d r}^{h o g, 1}$ and $\varepsilon_{d r}^{\text {hog,2 }}$ are the maximum shear strains in sagging and hogging obtained with Eq. (6). $\varepsilon_{\max }$ is a function of the random variables 
$\mathbf{X}=\left[V_{L} ; K ; \frac{E}{G} ; E_{\varepsilon_{b r}}^{s a g} ; E_{\varepsilon_{b r}}^{h o g, 1} ; E_{\varepsilon_{b r}}^{h o g, 2} ; E_{\varepsilon_{d r}}^{s a g} ; E_{\varepsilon_{d r}}^{h o g, 1} ; E_{\varepsilon_{d r}}^{h o g, 2}\right]$. The last six random variables in $\mathbf{X}$ are the errors of the equivalent beam model in individual zones of sagging and hogging. All these errors are assumed to be statistically independent.

Based on $\varepsilon_{\max }$, one can estimate the size of the cracks in the building. The approach of Burland et al. (1977) is used in this paper for classification of the damage magnitudes as shown in Table 1.

Table 1. Classification of damage (Burland et al., 1977)

\begin{tabular}{|c|c|c|c|c|}
\hline $\begin{array}{c}\text { Category } \\
\text { of damage }\end{array}$ & $\begin{array}{c}\text { Normal degree } \\
\text { of severity }\end{array}$ & Typical damage & $\begin{array}{c}\text { Tensile strain } \\
\boldsymbol{\varepsilon}_{\text {max }}(\%)\end{array}$ & $\boldsymbol{\varepsilon}_{\text {lim }}(\%)$ \\
\hline 0 & Negligible & Hair cracks less than $0.1 \mathrm{~mm}$ & $0-0.050$ & 0.050 \\
\hline 1 & Very slight & Fine cracks up to $1 \mathrm{~mm}$ & $0.050-0.075$ & 0.075 \\
\hline 2 & Slight & Cracks easily filled up to $5 \mathrm{~mm}$ & $0.075-0.150$ & 0.150 \\
\hline 3 & Moderate & Cracks from 5 to $15 \mathrm{~mm}$ & $0.150-0.300$ & 0.300 \\
\hline 4 & Severe & Extensive repair works. Cracks from 15 to $25 \mathrm{~mm}$ & $>0.300$ & - \\
\hline 5 & Very severe & Partial or complete rebuilding. Cracks $>25 \mathrm{~mm}$ & - & - \\
\hline
\end{tabular}

\subsection{Definition of intolerable damage}

The failure of the construction process $F$ is here defined as a situation when the tunneling causes an intolerable damage to the building.

The interest is in calculating the probability of an intolerable damage in the building due to the tunneling-induced settlements. It is assumed that intolerable damage $F$ occurs if the maximum strain $\left(\varepsilon_{\max }\right)$ according to Eq. (8) exceeds the limiting tensile strain value $\varepsilon_{\text {lim }}$ for a target category of damage (Table 1). In the following, we consider cracks with a width larger than $0.1 \mathrm{~mm}$ to be not tolerable; hence the limiting strain defining the intolerable damage is taken as $\varepsilon_{\text {lim }}=0.05 \%$.

To describe failure, the limit state function (LSF) is defined as

$g(\mathbf{X})=\varepsilon_{\text {lim }}-\varepsilon_{\max }(\mathbf{X})$

By definition, failure $F$ occurs when the LSF takes values smaller or equal to zero (Melchers, 1999). In the outcome space of the random variables $\mathbf{X}$, we can identify the failure domain $\Omega_{F}=\{g(\mathbf{x}) \leq 0\}$. The probability of intolerable damage hence equals the probability of $\mathbf{X}$ taking a value within the failure domain:

$\operatorname{Pr}(F)=\operatorname{Pr}\left(\mathbf{X} \in \Omega_{F}\right)$

Note that this definition of LSF is suitable when applying sampling methods for the computation of probabilities. If methods such as First-Order Reliability Method (FORM) were used, separate LSFs for $E_{\varepsilon_{b r}}^{s a g}, E_{\varepsilon_{b r}}^{h o g, 1}, E_{\varepsilon_{b r}}^{h o g, 2}, E_{\varepsilon_{d r}}^{s a g}, E_{\varepsilon_{d r}}^{h o g, 1}$ and $E_{\varepsilon_{d r}}^{h o g, 2}$ should be defined and the failure event should be described as a series system (Der Kiureghian, 2005). 


\section{Reliability-based criteria for settlement monitoring}

During the construction, measurements of the surface settlement are performed. These measurements are used to decide if the settlements are acceptable or if additional mitigation measures must be taken.

We denote by $S_{m}$ a settlement measurement that is used for the control of ground behavior in the vicinity of a building. It is taken at the position $\left(x_{m}, y_{m}, z_{m}\right)$, at the time when the tunnel face is located at $y_{s_{m}}$ as shown Figure 5. It is here assumed that the position of the measurement is so close to the analyzed building wall that the same ground behavior can be expected at the point of measurement and under the building. For this analysis it will be considered that $z_{m}=0$.

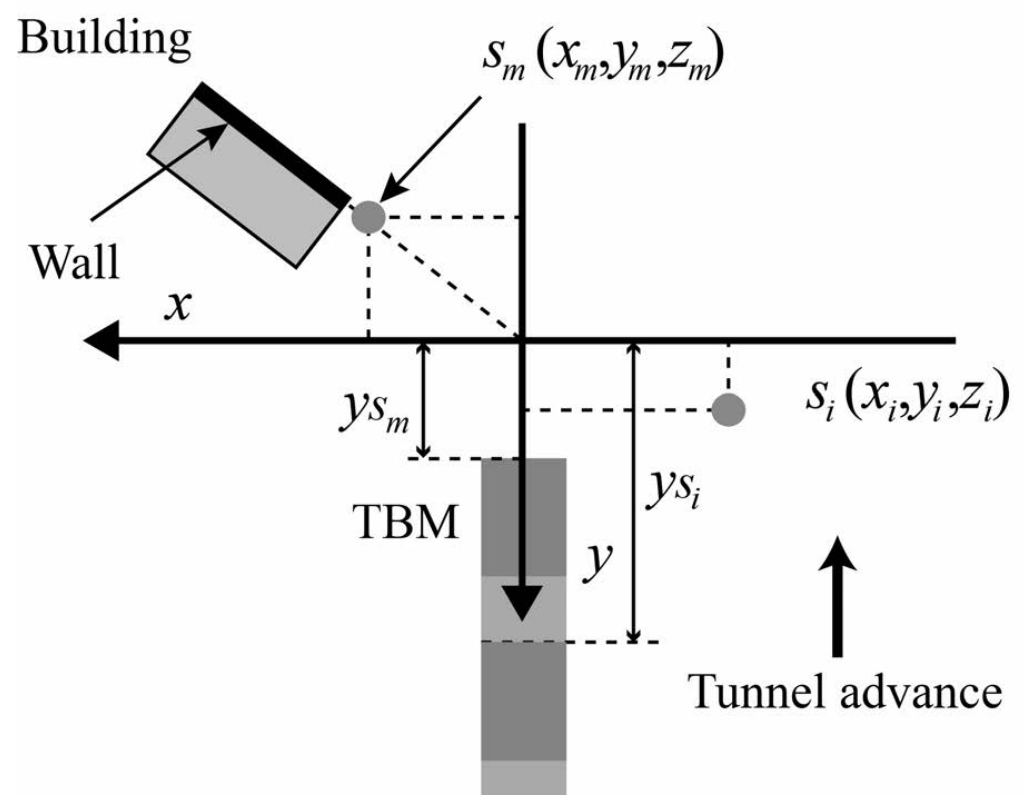

Figure 5. Position of the analyzed building, tunnel face, and measurements.

The quantity used for deciding if additional measures are necessary is the probability of failure $\operatorname{Pr}(F)$, i.e. the probability of intolerable damage. If this probability exceeds the target probability $p_{T}$, then measures must be taken. When a measurement $S_{m}$ is available, the relevant quantity becomes the conditional probability of failure given the measurement, $\operatorname{Pr}\left(F \mid S_{m}=s_{m}\right)$.

To facilitate application of this criterion in practice, one can determine a corresponding allowable settlement $s_{\text {lim }}$ from the following condition:

$\operatorname{Pr}\left(F \mid S_{m}=s_{\text {lim }}\right)=p_{T}$

Any measurement $s_{m}>s_{\text {lim }}$ implies that $\operatorname{Pr}\left(F \mid S_{m}=s_{\text {lim }}\right)>p_{T}$ and triggers further actions.

In Sec. 3.1, the computation of the allowable settlement $s_{\text {lim }}$ is presented. Sec. 3.2 describes the calculation of $s_{\text {lim }}$ when additional observations of settlement gathered during the tunnel construction (denoted as $s_{i}$ ) are taken into account. 


\subsection{Determination of the allowable settlement and effect of the measurement on the reliability}

The conditional probability of Eq. (11) can be determined by means of Bayesian updating techniques following Straub (2011). The approach was applied to geotechnical reliability with deformation measurements in Papaioannou and Straub (2012).

The relationship between the measured settlement $S_{m}$ and the settlement $S$ calculated according to Eq. (1) is:

$S_{m}=S\left(x_{m}, y_{m}, z_{m}, V_{L}, K\right)+E_{f}+E_{m}=S\left(x_{m}, y_{m}, z_{m}, V_{L}, K\right)+E_{E}$

where $E_{f}$ is the model error representing the deviation of the real settlement from the idealized Gaussian shape, and $E_{m}$ is the error of measurement on the site, which reflects imprecision of the instruments, human errors, effect of temperature changes. It is $E_{E}=E_{f}+E_{m}$.

The measurement $S_{m}$ is used to update the random variables volume loss $V_{L}$ and trough width parameter $K$ at the location of the measurement. The relation between the measurement $S_{m}$ and $V_{L}$ and $K$ can be described by a likelihood function. The likelihood function is the conditional probability density function (PDF) of the measurement outcome given particular values $V_{L}=v_{L}$ and $K=k$. By rearranging Eq.(12) we obtain $E_{E}=S_{m}-S\left(x_{m}, y_{m}, z_{m}, V_{L}, K\right)$. The PDF of the error $E_{E}$ is $f_{E}$. The likelihood function is therefore:

$L\left(v_{L}, k\right)=f_{E}\left(s_{m}-S\left(x_{m}, y_{m}, z_{m}, v_{L}, k\right)\right)$

Following Straub (2011), this likelihood function can be expressed by a LSF:

$h\left(v_{L}, k, u\right)=u-\Phi^{-1}\left[c L\left(v_{L}, k\right)\right]$

where $u$ is the realization of a standard normal $\mathrm{RV}, \Phi^{-1}$ is the inverse standard normal CDF and $c=\sigma_{E_{E}} \cdot \sqrt{2 \pi}$ is a scaling constant chosen to ensure that $c L\left(\left(v_{L}, k\right)\right) \leq 1$ for all $v_{L}, k$. This LSF defines the observation domain $\Omega_{0}=\left\{h\left(v_{L}, k, u\right) \leq 0\right\}$ in the outcome space of the RVs $\mathbf{X}$ and the standard normal variable $U$. The conditional probability of failure for a given settlement measurement $s_{m}$ is then computed as:

$\operatorname{Pr}\left(F \mid S_{m}=s_{m}\right)=\frac{\operatorname{Pr}\left(F \cap S_{m}=s_{m}\right)}{\operatorname{Pr}\left(S_{m}=s_{m}\right)}=\frac{\operatorname{Pr}\left([\mathbf{x}, u] \in\left\{\Omega_{0} \cap \Omega_{F}\right\}\right)}{\operatorname{Pr}\left([\mathbf{x}, u] \in \Omega_{0}\right)}$

where $\Omega_{F}$ is the failure domain defined by the LSF given in Eq. (9).

This conditional probability is evaluated with Monte Carlo Simulation(MCS) for different values of $s_{m}$. The allowable settlement value $s_{\text {lim }}$ ensuring Eq. (11) is then found iteratively.

\subsection{Including additional measurements at earlier locations}

Measurements of surface settlement are made during the whole construction process, not only in the vicinity of the analyzed building. All measurements that are taken in the quasi-homogeneous geotechnical section of the tunnel in which the analyzed building is located may be used to infer the behavior of the ground at the building. $N$ measurements $\mathbf{s}=\left(\mathrm{s}_{1}, \mathrm{~s}_{2}, \ldots, \mathrm{s}_{\mathrm{i}}, \ldots \mathrm{s}_{\mathrm{N}}\right)$ are obtained along the tunnel. The $i$-th measurement is made at position $x_{i}, y_{i}, z_{i}$, when the tunnel face is located at $y_{s_{i}}$ (see Figure 5). 
As above, the uncertain geotechnical conditions in the quasi-homogeneous section are characterized by volume loss $V_{L}$ and trough width parameter $K$. The values of these parameters vary even within a quasi-homogeneous section, due to random fluctuations. This variability of $V_{L}$ and $K$ is here described by stationary stochastic processes with constant autocorrelation functions $R_{K}(b)=\rho_{K}$ and $R_{V L}(b)=\rho_{V_{L}}$, where $b>0$ is the distance between two locations within the section. In other words, it is assumed that trough width parameter $K$ has the same marginal distribution at any location within the section and that the values of $K$ at two locations are correlated with correlation coefficients $\rho_{K}$, independent of the distance between them. The same holds for $V_{L}$. This simple correlation model was selected based on analysis of a small dataset from a constructed tunnel; it should be enhanced in the future based on the analysis of a larger amount of data.

The new measurements $\mathrm{s}_{1}, \ldots \mathrm{s}_{\mathrm{N}}$ can be expressed by separate likelihood functions $L_{1}, \ldots, L_{N}$, following Eq. (13). For each likelihood function $L_{i}$, one can find the corresponding observation domain $\Omega_{\mathrm{i}}$ defined by means of a LSF $h_{i}\left(v_{L_{i}}, k_{i}, u_{i}\right)$ as described in Eq. (14). Here, $v_{L_{i}}$ and $k_{i}$ are the realizations of the random processes $K$ and $V_{L}$ at the location $x_{i}, y_{i}, z_{i}$ of the measurement.

To update the maximum allowable settlement measurement at the position $\left(x_{m}, y_{m}, z_{m}\right)$ conditional on the existing measurements $\mathbf{s}$, the failure probability conditional on $s_{m}$ and $\mathbf{s}$ is computed (compare with Eq. (15)):

$$
\begin{aligned}
& \operatorname{Pr}\left(F \mid S_{m}=s_{m}, \mathbf{S}=\mathbf{s}\right)=\frac{\operatorname{Pr}\left(F \cap S_{m}=s_{m} \cap \mathbf{S}=\mathbf{s}\right)}{\operatorname{Pr}\left(S_{m}=s_{m} \cap \mathbf{S}=\mathbf{s}\right)} \\
& =\frac{\operatorname{Pr}\left(\left[\mathbf{x}, u, u_{1}, \ldots u_{N}\right] \in \Omega_{F} \cap \Omega_{\mathrm{O}} \cap \Omega_{1} \cap \ldots \cap \Omega_{N}\right)}{\operatorname{Pr}\left(\left[\mathbf{x}, u, u_{1}, \ldots u_{N}\right] \in \Omega_{\mathrm{O}} \cap \Omega_{1} \cap \ldots \cap \Omega_{N}\right)}
\end{aligned}
$$

Analogous to the procedure in Sec. 3.1, this conditional probability is evaluated for different values of $s_{m}$. The updated allowable settlement $s_{\text {lim }}^{*}$ ensuring Eq. (11) is found iteratively.

It is important to remark that the uncertainty of errors has computational implications. The calculation of $\operatorname{Pr}\left(F_{\varepsilon_{\text {lim }}} \mid s_{m}\right)$ is performed by using Eqs. (15) and (16): the total number of samples being in the failure and observation domains $\left(\Omega_{\mathrm{F}} \cap \Omega_{0}\right)$ is divided by the total number of samples in the observation domain $\Omega_{0}$. The acceptance of samples being in the observation domain $\Omega_{0}$ depends on the likelihood of the observations (Eq. (14)). Therefore, the higher the standard deviation of the errors, the higher is the number of samples included in $\Omega_{0}$. Low standard deviations of $E_{f}$ and $E_{m}$ will reduce substantially the number of samples fulfilling the condition to be in the observation domain $\Omega_{0}$ and thus, the accuracy of the determination of the probability of failure will be rather low. If computational efficiency were desirable, advanced sampling methods could be used instead of MCS for solving Eq. (15), see Straub (2011), Papaioannou and Straub (2012), Straub and Papaioannou (2014).

\section{Case study}

The proposed method is applied to a case study of the L9 metro line construction in Barcelona. The damage produced to a complex of attached masonry buildings from the late 1920's located in the Bon Pastor area is studied. Buildings were affected by the construction of a precast 
segment tunnel lining with an Earth Pressure Balance - Tunnel Boring Machine (EPB-TBM). An equivalent beam analysis of the buildings was performed in Camós et al. (2014), showing the validity of this model. The location of the buildings and the tunnel is shown in Figure 6 . The curvature of the tunnel axis is neglected in the following calculations. The analysis will be performed on the façade of 6 attached dwellings. The soil in the zone of study is characterized by the interbedding of sediment layers with a high variety of grain particle distributions such as grained sands, gravels, blocks in sandy matrix, clay and silts and coarse sands and gravels (Deulofeu et al. 2007).

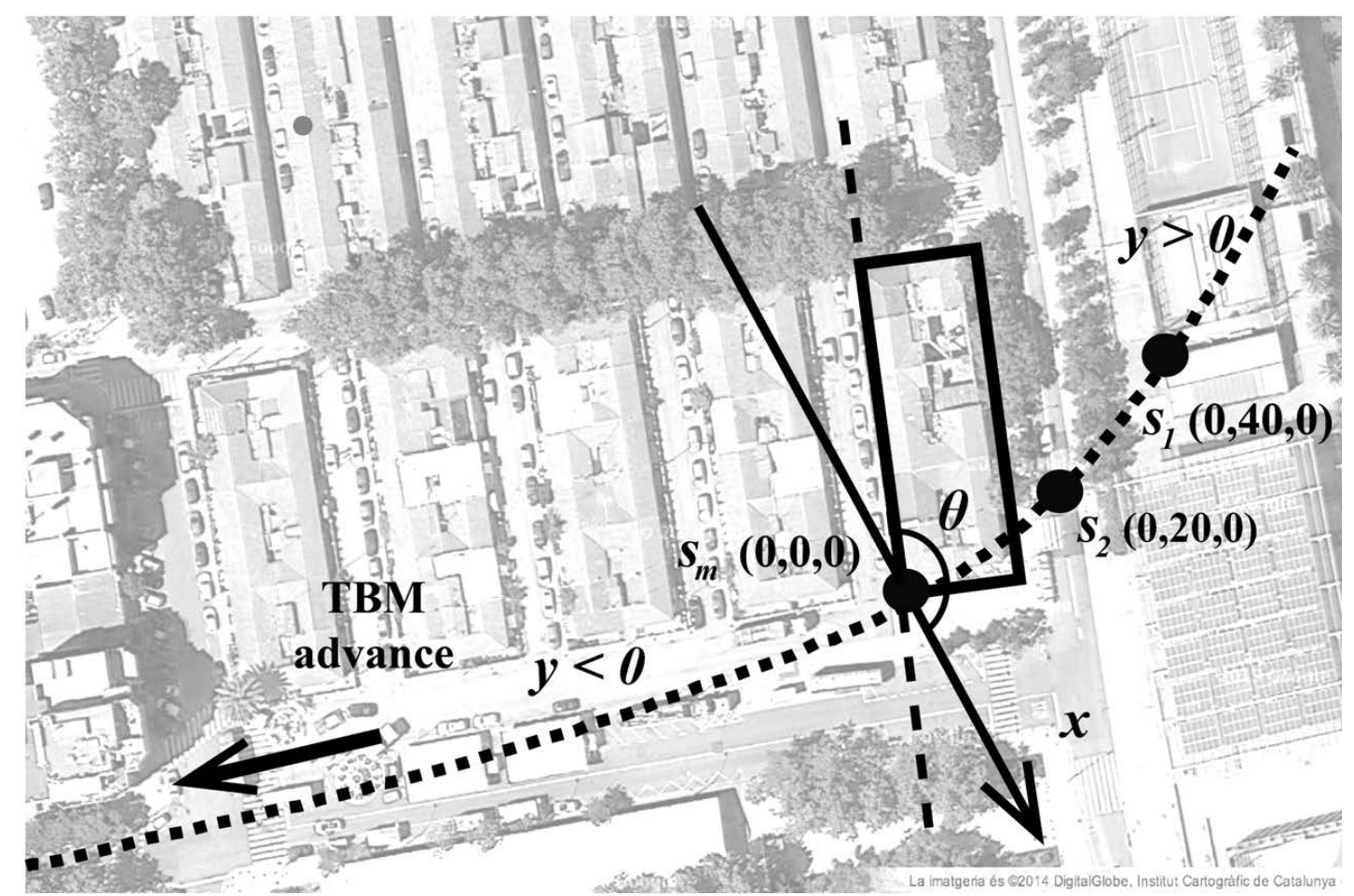

Figure 6. Location of attached buildings, tunnel track and position of measurements (dataset DS1) in Bon Pastor - Barcelona (source of the aerial map: DigitalGlobe ${ }^{\circledR 2014 ~-~ I n s t i t u t ~ C a r t o g r a ̀ f i c ~ d e ~ C a t a l u n y a) ~}$

\subsection{Model parameters}

The tunnel diameter $d$ in the studied section is $12 \mathrm{~m}$, the depth of the tunnel is $z_{0}=23 \mathrm{~m}$. The length of the building façade complex is $46 \mathrm{~m}$, the angle between the axes of the building and the tunnel is $\theta=154^{\circ}$. Note that due to symmetry about the $y$-axis, both alignments $\theta=154^{\circ}$ and $\theta=26^{\circ}$ are equivalent. The wall height is $H=3 \mathrm{~m}$ and it follows that the inertia per unit length of the cross-section of the wall is equal to $I=2.25 \mathrm{~m}^{4} / \mathrm{m}$. The parameter $t$ equals $1.5 \mathrm{~m}$ in the sagging zone and $3 \mathrm{~m}$ in the hogging zone and it is $a=t$ for both zones. The ratio between the surface settlement above the tunnel face and the maximal settlement is selected as $\delta=0.3$, which is a realistic value for the type of ground considered here (Nomoto et al. 1995, Fargnoli et al. 2013).

The parameters of the random variables considered in the model are summarized in Table 2 . The trough width parameter of the settlement profile $K$ usually varies in the range from 0.2 to 0.3 in case of granular soils, from 0.4 to 0.5 in case of stiff clays and it can reach a value of 0.7 in soft 
silty clays (Burland, 2008). The mean value of the trough width parameter $K$ is set at 0.3 and the coefficient of variation (c.o.v.) is assumed equal to $0.2 . K$ is non-negative and the lognormal distribution is thus used. A high spatial correlation of $K$ is assumed within the quasihomogeneous geotechnical section and the correlation coefficient of the underlying normal RV is thus set to $\rho_{K}=0.7$.

Experience from tunneling constructions in similar conditions (TYPSA, 2003) shows that the volume loss $V_{L}$ typically takes values in the range from $0.1 \%$ to $0.6 \%$. The uncertainty on these values is high due to many unpredictable factors that influence ground losses, including unexpected geological strata, technical problems of the TBM and human errors. $V_{L}$ is modeled by a lognormal distribution with mean $0.4 \%$ and c.o.v. $0.4 . V_{L}$ is primarily influenced by the construction process and it is typically highly variable within one quasi-homogeneous section. For this reason, the spatial correlation of the volume loss is assumed to be zero, $\rho_{V_{L}}=0$.

A value equal to 2.5 is typically assumed for the ratio $E / G$ of masonry buildings. Uncertainty is also present in this parameter due to the variety of orthotropic materials composing a building, yet this uncertainty is relatively small. Therefore, $E / G$ is here modeled by a beta distribution defined on the interval 2.4 to 2.6, which is a typical range of this ratio for masonry (Burland, 2008). Ideally, an unbounded distribution should be chosen, since the bounds imposed by the beta distribution are not physically justified. However, the effect of this modeling choice here is small.

The building is divided to one sagging and one hogging zone. Two values of extreme fiber strain in shear $\varepsilon_{d r}^{s a g}$ and $\varepsilon_{d r}^{h o g}$ and two values of extreme fiber strain in bending $\varepsilon_{b r}^{s a g}$ and $\varepsilon_{b r}^{\text {hog }}$ are thus computed using the equivalent beams model following Eqs.(5)-(7). The multiplicative model errors of the model $E_{\varepsilon_{b r}}^{s a g}, E_{\varepsilon_{d r}}^{s a g}, E_{\varepsilon_{b r}}^{\text {hog }}, E_{\varepsilon_{d r}}^{\text {hog }}$, are described by lognormal distributions with mean equal to 1 and st.dev. 0.05 . The errors are assumed to be independent.

Table 2. Random parameters of the model.

\begin{tabular}{|l|l|l|l|l|}
\hline \multicolumn{1}{|c|}{ Parameter [units] } & \multicolumn{1}{c|}{ Description } & \multicolumn{1}{c|}{ Distribution } & Mean & St. dev. \\
\hline $\boldsymbol{K}[-]$ & Trough width parameter & lognormal $(-1.22,0.20)$ & 0.3 & 0.06 \\
\hline $\boldsymbol{V}_{\boldsymbol{L}}[\%]$ & Volume loss & lognormal $(-0.99,0.39)$ & 0.4 & 0.16 \\
\hline $\boldsymbol{E} / \boldsymbol{G}[-]$ & Material ratio & beta $(2,2,[2.4,2.6])$ & 2.5 & 0.045 \\
\hline $\boldsymbol{E}_{m}[\mathrm{~mm}]$ & Measurement error & normal $(0.0,1)$ & 0.0 & 1 \\
\hline $\boldsymbol{E}_{f}[\mathrm{~mm}]$ & Settlement model error & normal $(0.0,2)$ & 0.0 & 2 \\
\hline $\boldsymbol{E}_{\boldsymbol{\varepsilon}_{b r}}^{\text {sag }}, \boldsymbol{E}_{\varepsilon_{d r}}^{\text {sag }}, \boldsymbol{E}_{\boldsymbol{\varepsilon}_{b r}}^{\text {hog }}, \boldsymbol{E}_{\boldsymbol{\varepsilon}_{d r}}^{\text {hog }}[-]$ & Eq. beam model errors & lognormal $(0.0,0.05)$ & 1.0 & 0.05 \\
\hline
\end{tabular}

The results of the analyses performed in the following paper are achieved with $5 \cdot 10^{6}$ simulations. The building is discretized in 50 calculation points. The computing time is about one hour by using a computer with Intel Core i7 930 @ $2.80 \mathrm{GHz}$ processor, 8GB RAM and operating system Windows 7 Professional 64 bits.

For simplicity, the following calculations take into account the whole length of the building. However, in case of long buildings as the analyzed one, the part of the building subjected to settlements lower than $1 \mathrm{~mm}$ should be disregarded in order to avoid the possible overestimation of $\varepsilon_{\text {bmax }}$ and $\varepsilon_{d \max }$ and the underestimation of $\varepsilon_{h}$ (see Camós and Molins, 2015). 


\subsection{Probabilistic prediction of settlement and building damage}

A probabilistic prediction of settlement at the location of the building $(x, y, z)=(0,0,0)$ is performed by using the Eq. (1). Figure 7 shows the cumulative distribution functions of the predicted settlement $S_{(0,0,0)}$ for different positions of the tunnel face $y_{s}$, Table 3 summarizes its mean and standard deviation. The predicted mean values of settlement vary from $0.6 \mathrm{~mm}$ for the case when the tunnel face is 10 meters before the building $\left(y_{s}=+10\right)$ to $27 \mathrm{~mm}$ for the case when the tunnel face passed under the building and it is 50 meters behind $\left(y_{s}=-50 \mathrm{~m}\right)$. The difference of the settlement for $y_{s}=-20 \mathrm{~m}$ and $y_{s}=-50 \mathrm{~m}$ is very low, which indicates that at these distances, the maximal settlement $S_{\max }$ is reached.

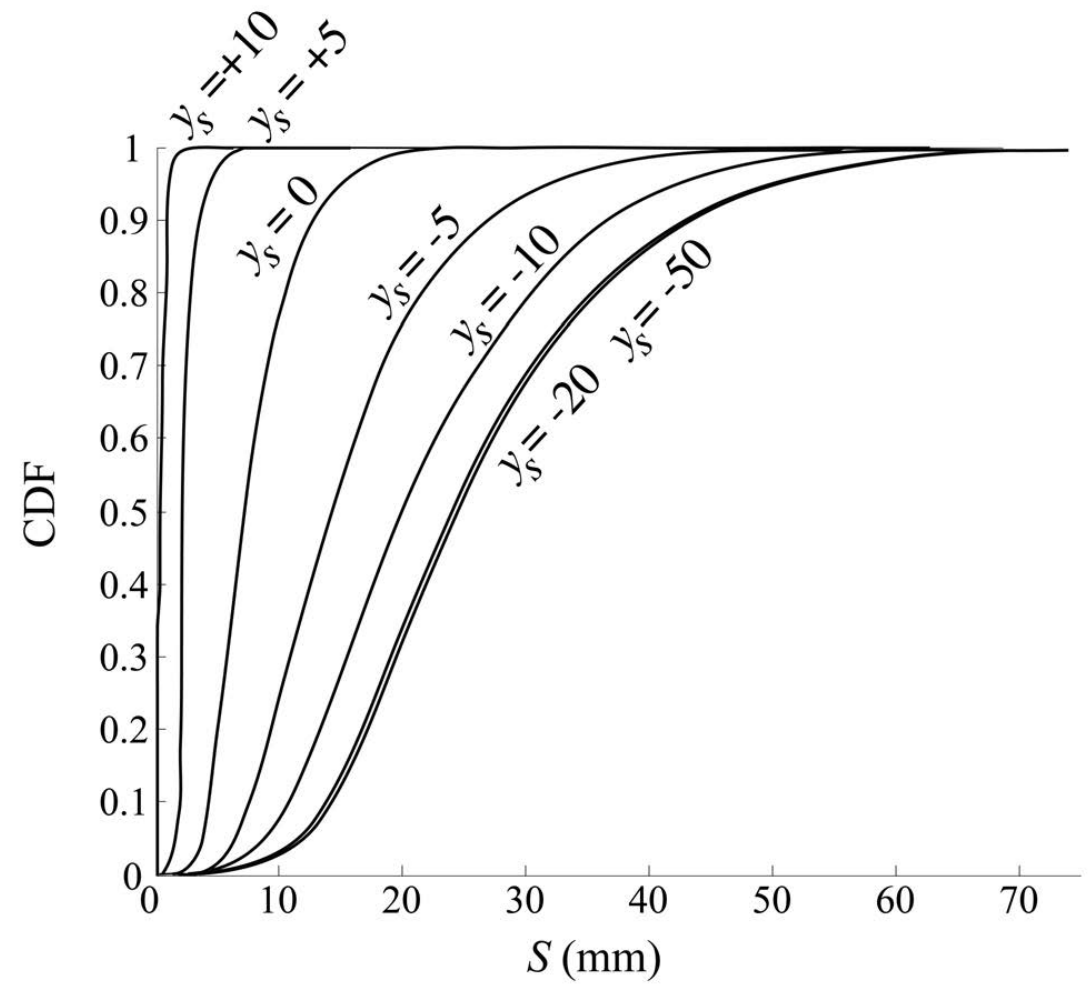

Figure 7. Cumulative distribution function of settlement $S_{(0,0,0)}$ for different positions of the tunnel face $y_{s}$. Means and standard deviations of the settlements are summarized in Table 3.

Table 3. Mean and standard deviation of settlement $S_{(0,0,0)}$ for different positions of the tunnel face $y_{s}$.

\begin{tabular}{|c|c|c|}
\hline Position of tunnel face $\boldsymbol{y}_{\boldsymbol{s}}(\mathbf{m})$ & Mean $(\mathbf{m m})$ & St. dev. $(\mathbf{m m})$ \\
\hline+10 & 0.6 & 0.4 \\
\hline+5 & 2.7 & 1.1 \\
\hline 0 & 8.2 & 3.7 \\
\hline-5 & 16.3 & 8.6 \\
\hline-10 & 22.8 & 11.6 \\
\hline-20 & 26.9 & 12.6 \\
\hline-50 & 27.2 & 12.5 \\
\hline
\end{tabular}


Only a negligible damage (Category 0) is considered as acceptable, as is usual in tunneling construction. More severe damages to buildings are considered as intolerable, therefore the limiting tensile strain is set to $\varepsilon_{\text {lim }}=0.05 \%$ following Table 1 .

The prior probabilities of intolerable damage calculated using Eq. (10) are shown in Table 4. It can be seen that for positions of the tunnel face $y_{s}<0$, the probability of damage is in the order of $25 \%$. This high probability of damage is due to the large uncertainties of the ground behavior and of the measurement and model errors as well as due to the strict definition of intolerable damage (category 1 or higher of Table 1). Note that the probability of intolerable damage is slightly higher if tunnel face is located at $y_{s}=-10 \mathrm{~m}$ than at $y_{s}=-20 \mathrm{~m}$. This difference is due to the alignment of the building with respect to the tunnel axis $\left(\theta=26^{\circ}\right)$. The combination of deflection ratios and ground horizontal strain $\varepsilon_{h}$ at the wall results to be more critical when tunnel face is at $y_{s}=-10 \mathrm{~m}$ than when it is at $y_{s}=-20 \mathrm{~m}$.

Table 4. Unconditional probabilities of intolerable damage for different positions of the tunnel face.

\begin{tabular}{|c|c|c|c|c|c|c|}
\hline Position of tunnel face & $\boldsymbol{y}_{\boldsymbol{s}}=+\mathbf{1 0 m}$ & $\boldsymbol{y}_{\boldsymbol{s}}=+\mathbf{5} \mathbf{m}$ & $\boldsymbol{y}_{\boldsymbol{s}}=\mathbf{0 m}$ & $\boldsymbol{y}_{\boldsymbol{s}}=-\mathbf{5 m}$ & $\boldsymbol{y}_{\boldsymbol{s}}=-\mathbf{1 0 m}$ & $\boldsymbol{y}_{\boldsymbol{s}}=\mathbf{- 2 0} \mathbf{m}$ \\
\hline Probability of damage $\operatorname{Pr}(\boldsymbol{F})$ & $0 \%$ & $0.01 \%$ & $8 \%$ & $23 \%$ & $28 \%$ & $25 \%$ \\
\hline
\end{tabular}

\subsection{A-priori determination of the allowable settlement}

We are looking for allowable settlement $s_{\text {lim }}$ at the position $\left(x_{m}, y_{m}, z_{m}\right)=(0,0,0)$ that satisfies Eq. (11). The target probability for intolerable damage is set to $p_{T}=5 \%$.

The allowable settlement is determined using the approach described in Sec. 3.1. The probability of damage conditional on measured settlements $s_{m}$ is calculated following Eq. (15), the results for $s_{m}$ in the interval from 0 to $40 \mathrm{~mm}$ are displayed in Figure 8 for different positions of the tunnel face.

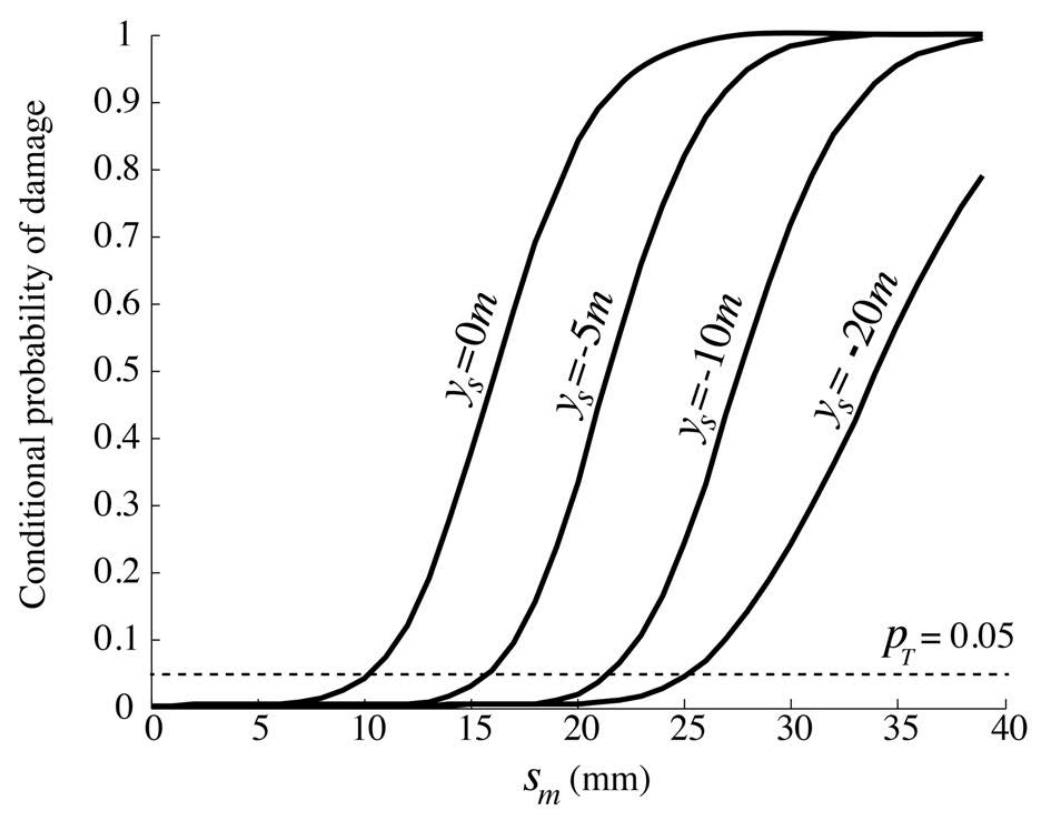

Figure 8. Conditional probability of intolerable damage $\operatorname{Pr}\left(F_{\varepsilon_{l i m}=0.050 \%} \mid s_{m}\right)$ as a function of measured settlement $s_{m}$ for different positions of tunnel face $y_{s}$. 
The allowable settlement $s_{\text {lim }}$ for each location of the tunnel face $y_{s}$ can be determined from the intersection of the relevant probability curve with the $p_{T}$ line. The results are summarized in Table 5. For example, for $y_{s}=-20 \mathrm{~m}$, i.e. for the case when the tunnel face is $20 \mathrm{~m}$ behind the building and the settlement is almost fully developed, the allowable settlement $s_{\text {lim }}$ is $25 \mathrm{~mm}$. On the contrary, for $y_{s}=0 \mathrm{~m}$, i.e. for the case when the tunnel face is beneath the building, the allowable settlement $s_{\text {lim }}$ is $10 \mathrm{~mm}$. The generated settlements in the zone of analysis when the tunnel face is still far are generally small due to the shift of the longitudinal profile $(\delta=0.3)$. Hence, the measurements will have limited expressiveness with the presented model. For this reason, the measurement error will dominate at these locations and no measurement will sufficiently reduce the probability of intolerable damage. Therefore, the analysis at tunnel face locations $y_{s}=+5 \mathrm{~m}$ and $y_{s}=+10 \mathrm{~m}$ is not performed in the following.

Table 5. Prior values of allowable settlement for different locations of tunnel face.

\begin{tabular}{|l|c|c|c|c|}
\hline Position of tunnel face & $\boldsymbol{y}_{\boldsymbol{s}}=\mathbf{0 m}$ & $\boldsymbol{y}_{\boldsymbol{s}}=\mathbf{- 5 m}$ & $\boldsymbol{y}_{\boldsymbol{s}}=\mathbf{- 1 0 \mathrm { m }}$ & $\boldsymbol{y}_{\boldsymbol{s}}=\mathbf{- 2 0 \mathrm { m }}$ \\
\hline Prior allowable settlement, $\boldsymbol{s}_{\text {lim }}$ & $10 \mathrm{~mm}$ & $15 \mathrm{~mm}$ & $21 \mathrm{~mm}$ & $25 \mathrm{~mm}$ \\
\hline
\end{tabular}

\subsection{Updating with observations from monitoring instruments}

The prior estimation of the allowable settlement is updated with earlier measurements made in other locations within the same quasi-homogeneous section of the tunnel, following the procedure described in Sec. 3.2. For the numerical investigation, two different data sets denoted as DS1 and DS2 are used.

DS1 consists of two real measurements of the settlement performed in the same quasihomogeneous section (Figure 6): measurement $s_{1}=11 \mathrm{~mm}$ was taken at position $\left(x_{1}, y_{1}, z_{1}\right)=$ $(0,40,0)$ and measurement $s_{2}=19 \mathrm{~mm}$ was taken at $\left(x_{2}, y_{2}, z_{2}\right)=(0,20,0)$, as shown in Figure 6 . Both measurements were made at the moment when the tunnel face was under the location of the measurement, therefore $y_{s_{1}}=+40 \mathrm{~m}$ and $y_{s_{2}}=+20 \mathrm{~m}$.

DS2 is a hypothetical data set, introduced for illustration purposes. The measured settlement values are: $s_{1}=19 \mathrm{~mm}$ taken at position $\left(x_{1}, y_{1}, z_{1}\right)=(7,20,0), s_{2}=18 \mathrm{~mm}$ taken at position $\left(x_{2}, y_{2}, z_{2}\right)=(0,40,0)$ and $s_{3}=19 \mathrm{~mm}$ taken at position $\left(x_{3}, y_{3}, z_{3}\right)=(-8,20,0)$. Measurements $s_{1}$ and $s_{3}$ are taken close to the inflection point of the transverse Gaussian settlement profile, whereas $S_{2}$ is taken at tunnel centerline. All three measurements are taken at the moment when the tunnel face is underneath the building, so that $y_{s_{1}}=y_{s_{2}}=y_{s_{3}}=0 \mathrm{~m}$. DS2 indicates a higher volume loss and a flatter settlement profile than DS1.

Table 6 shows the updated values of allowable settlement with the two datasets. Accounting for the measurements DS1 slightly reduces the allowable values of settlement compared to the prior values shown in Table 5. Accounting for the measurements DS2 slightly increases these values. The reason for these opposite trends is the posterior distribution of the trough width parameter $K$ at the location of the building, conditional on DS1 or DS2; its CDF is presented in Figure 9. It can be observed that the measurements DS1 lead to a lower posterior estimate of $K$ indicating a sharper profile, whereas DS2 lead to a higher posterior estimate of $K$ indicating a flatter profile. The sharper profile is more critical for the buildings since it produces higher deflection ratios and thus more severe damages. Because the volume loss $V_{L}$ is not correlated from one location to another, only the trough width parameter $K$ can be learned. Overall it can be observed that with 
the assumed correlation model, the overall effect of the additional measurements is relatively small.

Table 6. Values of allowable settlement $s_{\text {lim }}$ for different locations of tunnel face updated with the two datasets.

\begin{tabular}{|l|c|c|c|c|}
\hline Position of tunnel face & $\boldsymbol{y}_{\boldsymbol{s}}=\mathbf{0 m}$ & $\boldsymbol{y}_{\boldsymbol{s}}=-\mathbf{5 m}$ & $\boldsymbol{y}_{\boldsymbol{s}}=\mathbf{- 1 0 m}$ & $\boldsymbol{y}_{\boldsymbol{s}}=\mathbf{- 2 0 m}$ \\
\hline $\boldsymbol{s}_{\text {lim }}$ updated with DS1 & $8 \mathrm{~mm}$ & $14 \mathrm{~mm}$ & $20 \mathrm{~mm}$ & $23 \mathrm{~mm}$ \\
\hline $\boldsymbol{s}_{\text {lim }}$ updated with DS2 & $11 \mathrm{~mm}$ & $16 \mathrm{~mm}$ & $22 \mathrm{~mm}$ & $26 \mathrm{~mm}$ \\
\hline
\end{tabular}

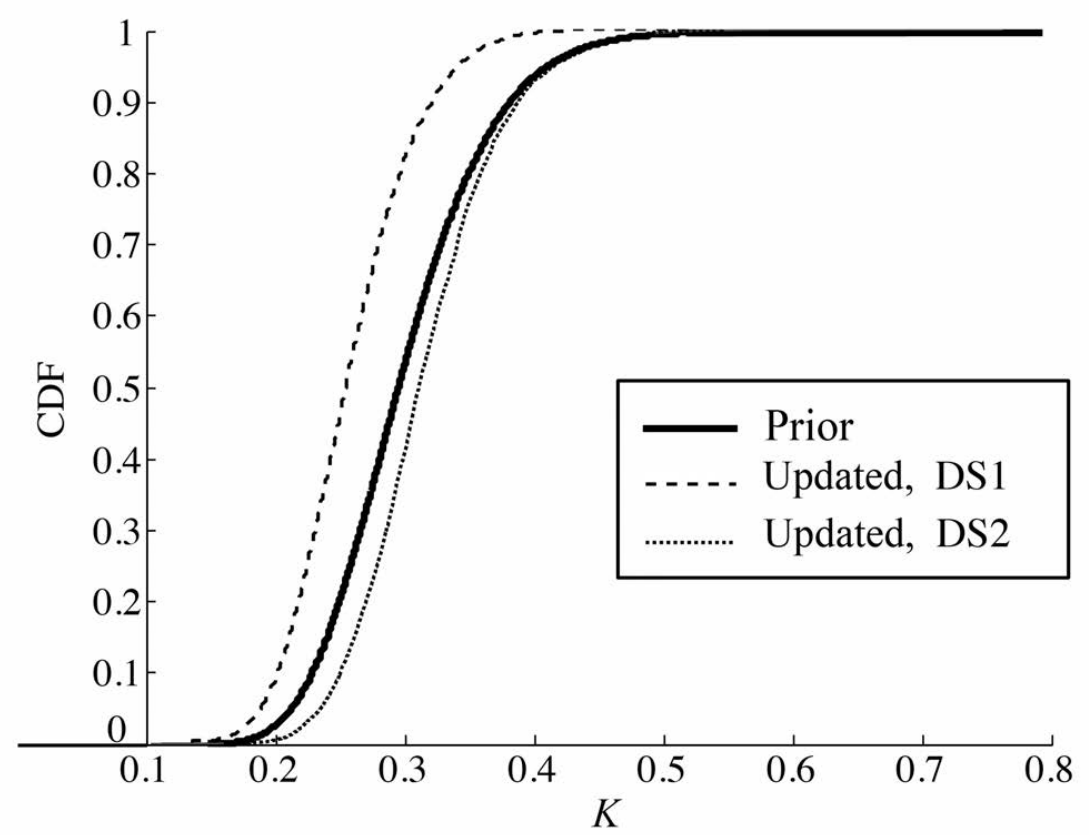

Figure 9. Prior and updated cumulative density function of trough width parameter $K$.

\section{Parametric study}

In this section, the influence of selected model parameters on the allowable settlement is examined.

5.1 Influence of the shift of the longitudinal Gaussian settlement profile characterized by parameter $\delta$

Following Eq. (4), the parameter $\delta$ defines the ratio between the immediate surface settlement above the tunnel face and the maximal settlement $S_{\max }$ at a location far from the face. In Sections 4.1-4.4 it was assumed that $\delta=0.3$, i.e. that at the moment when the tunnel face is under the location of interest, the settlement at this location corresponds to $30 \%$ of the final/maximal settlement $S_{\max }$. The longitudinal Gaussian settlement profile is thus shifted in the horizontal direction as illustrated in Figure 4. In the practice, however, it is common to assume $\delta=0.5$. The influence of this assumption is tested here.

Table 7 shows the a-priori allowable settlement $s_{\text {lim }}$ for both $\delta=0.3$ and $\delta=0.5$. The allowable settlement for $\delta=0.5$ for positions of tunnel face close to the analyzed building, i.e. for $y_{s}$ being 
in the interval from $y_{s}=+0 \mathrm{~m}$ to $y_{s}=-10 \mathrm{~m}$, are higher than for $\delta=0.3$. The reason for the higher allowable values in case of $\delta=0.5$ is that we assume an earlier development of the settlement ( $50 \%$ of the final settlement at the moment when the face undergoes the building) and thus a smaller increase of the settlement after the tunnel face passes the building. A higher settlement is thus acceptable.

Table 7. Prior values of allowable settlement for different locations of tunnel face for different values of $\delta$.

\begin{tabular}{|c|c|c|c|c|}
\hline Ratio $\boldsymbol{\delta} \backslash$ Position of tunnel face & $\boldsymbol{y}_{\boldsymbol{s}}=\mathbf{0 m}$ & $\boldsymbol{y}_{\boldsymbol{s}}=-\mathbf{5 m}$ & $\boldsymbol{y}_{\boldsymbol{s}}=-\mathbf{1 0 m}$ & $\boldsymbol{y}_{\boldsymbol{s}}=-\mathbf{2 0 m}$ \\
\hline $\boldsymbol{\delta}=\mathbf{0 . 3}$ & $10 \mathrm{~mm}$ & $15 \mathrm{~mm}$ & $21 \mathrm{~mm}$ & $25 \mathrm{~mm}$ \\
\hline $\boldsymbol{\delta}=\mathbf{0 . 5}$ & $13 \mathrm{~mm}$ & $19 \mathrm{~mm}$ & $23 \mathrm{~mm}$ & $25 \mathrm{~mm}$ \\
\hline
\end{tabular}

\subsection{Influence of the uncertainty of ground parameters $V_{L}$ and $K$}

In the Gaussian profile model of tunneling induced settlement, the ground is described by volume loss $V_{L}$ and trough width parameter $K$, as discussed in Section 2.1, which are here modeled probabilistically, following Table 2. To assess the influence of the assumptions on the uncertainty in $V_{L}$ and $K$, the computations are repeated with the standard deviations of these variables doubled, from $\sigma_{K}=0.06$ to $\sigma_{K}=0.12$, and from $\sigma_{V_{L}}=0.16$ to $\sigma_{V_{L}}=0.32$. (The parameters of the corresponding lognormal distributions are $\mu_{K}^{\prime}=-1.28, \sigma_{K}^{\prime}=0.39$, and $\mu_{V_{L}}^{\prime}=-$ 1.16, $\sigma_{V_{L}}^{\prime}=0.7$.)

A comparison of the resulting allowable settlements obtained with the original model to those from the modified model is shown in Table 8. It can be seen that increasing the standard deviation of the RVs leads to stricter (lower) limits on the allowable settlement, because a higher uncertainty on the ground behavior causes a higher probability of intolerable damage. Increasing the standard deviation of both $V_{L}$ and $K$ by a factor of two leads to a reduction of the allowable settlement by $10 \%-30 \%$.

Table 8. Prior values of allowable settlement for different positions of tunnel face for different standard deviations of the ground parameters $V_{L}$ and $K$.

\begin{tabular}{|c|c|c|c|c|}
\hline Uncertainty on ground parameters \Position of tunnel face & $\boldsymbol{y}_{\boldsymbol{s}}=\mathbf{0 m}$ & $\boldsymbol{y}_{\boldsymbol{s}}=\mathbf{- 5 m}$ & $\boldsymbol{y}_{\boldsymbol{s}}=\mathbf{- 1 0 m}$ & $\boldsymbol{y}_{\boldsymbol{s}}=\mathbf{- 2 0 m}$ \\
\hline $\begin{array}{l}\sigma_{K}=0.06 \\
\sigma_{V_{L}}=0.16\end{array}$ & $10 \mathrm{~mm}$ & $15 \mathrm{~mm}$ & $21 \mathrm{~mm}$ & $25 \mathrm{~mm}$ \\
\hline $\begin{array}{l}\sigma_{K}=0.12 \\
\sigma_{V_{L}}=0.32\end{array}$ & $7 \mathrm{~mm}$ & $13 \mathrm{~mm}$ & $18 \mathrm{~mm}$ & $19 \mathrm{~mm}$ \\
\hline
\end{tabular}

\subsection{Influence of the correlation coefficients $\rho_{V_{L}}$ and $\rho_{K}$}

The spatial correlation of the geotechnical parameters volume loss $V_{L}$ and trough width parameter $K$ is modeled by means of a constant autocorrelation function as described in Section 3.2. The spatial correlation determines the effect of measurements made at other locations of the quasi-homogeneous section on the probabilistic model, and consequently the allowable settlement, at the location of interest. Earlier it was assumed that the trough width parameter $K$ is correlated with correlation coefficient $\rho_{K}=0.7$ and the volume loss $V_{L}$ is uncorrelated, therefore $\rho_{V_{L}}=0$. This implies that learning of $V_{L}$ based on measurements from other locations was not possible. 
To assess the effect of the correlation, the correlation coefficient of $V_{L}$ is modified to 0.7 , whereas the one for $K$ is kept, i.e. $\rho_{K}=\rho_{V_{L}}=0.7$. The resulting allowable settlements are summarized in Table 9. It can be observed that the higher correlation leads to a slight increase in the allowable settlements. With the higher correlation, the uncertainty in $V_{L}$ at the location of interest is reduced, as evident from Figure 10.

Table 9. Updated values of allowable settlement for different positions of tunnel face for different correlation coefficients $\rho_{V_{L}}$ and $\rho_{K}$.

\begin{tabular}{|c|c|c|c|c|c|}
\hline & Position of tunnel face & $y_{s}=0 \mathrm{~m}$ & $y_{s}=-5 \mathrm{~m}$ & $y_{s}=-10 \mathrm{~m}$ & $y_{s}=-20 \mathrm{~m}$ \\
\hline \multirow{2}{*}{$\begin{array}{c}\rho_{K}=0.7 \\
\rho_{V_{L}}=0\end{array}$} & $s_{\text {lim }}$ updated with DS1 & $8 \mathrm{~mm}$ & $14 \mathrm{~mm}$ & $20 \mathrm{~mm}$ & $23 \mathrm{~mm}$ \\
\hline & $s_{\text {lim }}$ updated with DS2 & $11 \mathrm{~mm}$ & $16 \mathrm{~mm}$ & $22 \mathrm{~mm}$ & $26 \mathrm{~mm}$ \\
\hline \multirow{2}{*}{$\begin{array}{l}\rho_{K}=0.7 \\
\rho_{V_{L}}=0.7\end{array}$} & $s_{\text {lim }}$ updated with DS1 & $8 \mathrm{~mm}$ & $15 \mathrm{~mm}$ & $21 \mathrm{~mm}$ & $24 \mathrm{~mm}$ \\
\hline & $s_{\text {lim }}$ updated with DS2 & $12 \mathrm{~mm}$ & $18 \mathrm{~mm}$ & $24 \mathrm{~mm}$ & $29 \mathrm{~mm}$ \\
\hline
\end{tabular}

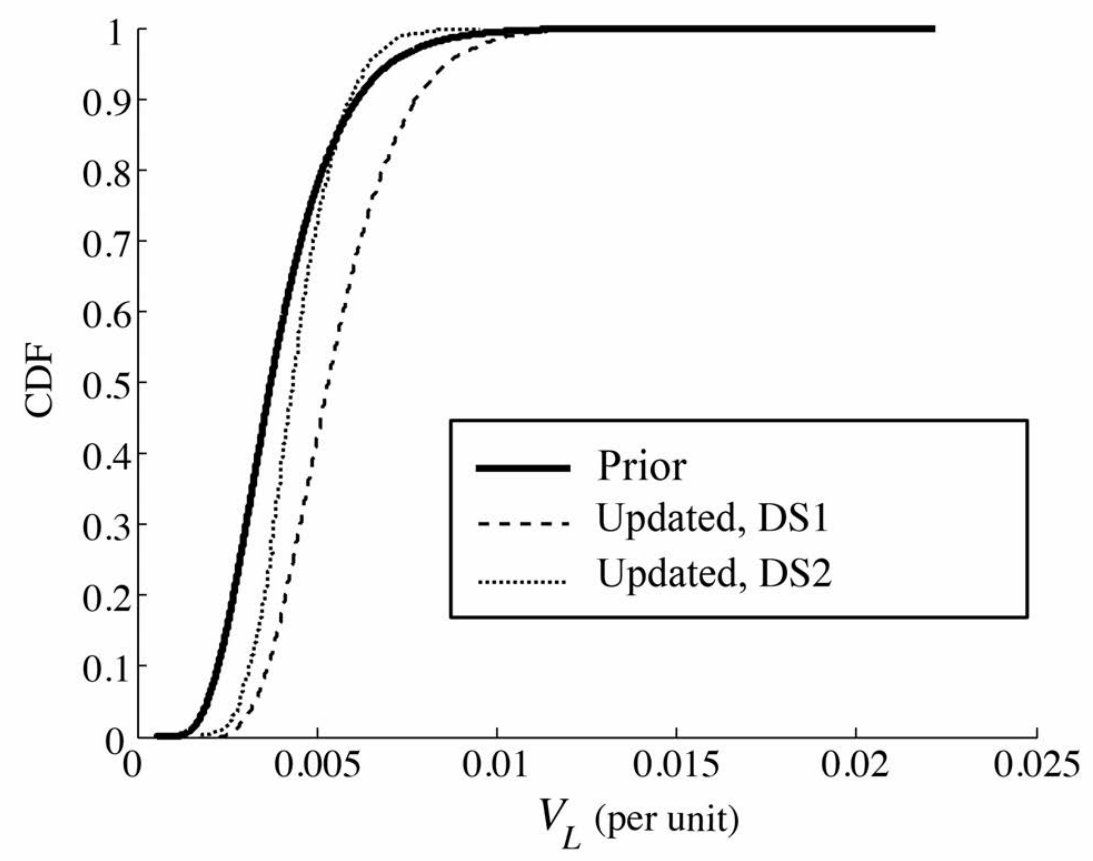

Figure 10. Prior and updated cumulative density function of $V_{L}$ with $\rho_{V_{L}}=0.7$

\subsection{Influence of the uncertainty of the model error $E_{f}$ and measurements error $E_{m}$}

The determination of allowable settlements is based on the probability of damage conditional on measured settlements $s_{m}$, Eq. (11). This probability can be determined by reliability updating techniques based on the likelihood of a certain observation $s_{m}$, Eq. (13). This likelihood is defined as the probability of having a certain error between the measured settlement $s_{m}$ and the settlement $S$ given by the Gaussian profile model. Therefore, the PDF of the total error $E_{E}$ depends on the distribution parameters of the ground model error $E_{f}$ and the measurement error $E_{m}$. These errors are considered as random with normal distribution and mean and standard deviation according to Table 2: the measurement error $E_{m}$ was assumed to have a standard deviation of $1 \mathrm{~mm}$ while the model error $E_{f}$ a standard deviation of $2 \mathrm{~mm}$. 
To investigate the effect of the distribution of these errors, computations are repeated with reduced standard deviations of the errors. Table 10 compares the allowable values for the original assumption with the case in which the standard deviations of both errors are decreased to $50 \%$ of the original value. As can be observed, the higher the uncertainty on the model errors, the lower the allowable values of settlements $s_{\text {lim }}$, but the difference among the two investigated cases is low.

Table 10. Prior values of allowable settlement $s_{\text {lim }}$ for different positions of tunnel face for different standard deviations of the measurement error $E_{m}$ and of the ground model error $E_{f}$.

\begin{tabular}{|c|c|c|c|c|}
\hline $\begin{array}{c}\text { Position of tunnel } \\
\text { face }\end{array}$ & $\boldsymbol{y}_{\boldsymbol{s}}=\mathbf{0 m}$ & $\boldsymbol{y}_{\boldsymbol{s}}=\mathbf{- 5 \mathrm { m }}$ & $\boldsymbol{y}_{\boldsymbol{s}}=\mathbf{- 1 0 \mathrm { m }}$ & $\boldsymbol{y}_{\boldsymbol{s}}=\mathbf{- 2 0 \mathrm { m }}$ \\
\hline $\begin{array}{c}\sigma_{\boldsymbol{E}_{f}}=2 \mathrm{~mm} \\
\sigma_{\boldsymbol{E}_{m}}=1 \mathrm{~mm}\end{array}$ & $10 \mathrm{~mm}$ & $15 \mathrm{~mm}$ & $21 \mathrm{~mm}$ & $25 \mathrm{~mm}$ \\
\hline $\begin{array}{c}\sigma_{\boldsymbol{E}_{f}}=1 \mathrm{~mm} \\
\sigma_{\boldsymbol{E}_{m}}=0.5 \mathrm{~mm}\end{array}$ & $10 \mathrm{~mm}$ & $16 \mathrm{~mm}$ & $22 \mathrm{~mm}$ & $26 \mathrm{~mm}$ \\
\hline
\end{tabular}

\section{Discussion}

In the case study, the allowable value of settlement is determined as $25 \mathrm{~mm}$ for positions where the settlement is fully developed (far from the tunnel heading). This value corresponds well with the allowable settlement that was used during the construction $(24 \mathrm{~mm})$. For buildings with shallow foundations and deteriorated initial states, a more restrictive allowable settlement value of 8mm was employed. Indeed, the foundations and the initial state of the buildings may play an important role on the structural response of buildings. The modeling of these aspects by means of equivalent beam method is limited. In such cases, an engineering judgment can be used to decrease the allowable settlement to more reasonable values. Alternatively, the reliability based approach for determining the allowable value of settlement proposed in this paper can be combined with more advanced physical models of the ground and building behavior. To keep the computational costs reasonable, the Monte Carlo approach utilized in this paper would have to be replaced with more efficient methods such as subset simulation (see Section 3).

The parametric analysis in Sec. 5 has shown the influence of the model parameters on the determination of allowable settlements. Variations of the $\delta$ ratio, the measurement error $E_{m}$ and the ground model error $E_{f}$ have little effect on the allowable settlements, whereas the uncertainty of ground parameters $\left(K, V_{L}\right)$ and the correlation coefficients $\left(\rho_{K}, \rho_{V_{L}}\right)$ show a more significant influence. However, the changes in the results with the different assumptions are generally limited, which indicates that the method is applicable even when limited information about the site is available.

It was shown in Table 4 that a-priori, i.e. before the measurements, the probability of intolerable damage is higher than the selected value of $p_{T}(5 \%)$. For this reason, the resulting allowable settlement values $s_{\text {lim }}$ are always stricter (lower) than the expected settlement values $S$ shown in Table 3. Therefore, the selected value of $p_{T}$ could be seen as too strict. An improved choice of the target probability for intolerable damage $p_{T}$ could be obtained by means of a risk-based approach. Expected monetary damages and consequences should be considered in a decision analysis for evaluating the optimality of decision alternatives. Mitigation measures could be 
implemented, such as the stabilization of ground with retaining walls or grout injection, and the cost of such measures should be compared against the risks incurred by continuing the construction process without them. The probability of intolerable damage could then be substituted by a threshold value for the acceptable risk. Such an approach could be implemented into practice by means of specific software used at tunnel construction control. This software would contain information about the probabilistic model shown throughout this paper and a database of those buildings that are potentially subjected to ground subsidence. Monitoring data gathered during the excavation would be used for updating of the probabilistic model. The existing risk at every location of tunnel face would be quantified and compared with the threshold value to decide whether the excavation should continue or mitigation measures should be implemented.

\section{Conclusion}

The paper presented a model for probabilistic prediction of building damage due to tunneling that is applicable in engineering practice (Sec. 2). A Gaussian profile model was used to simulate the settlement trough produced by tunneling. The equivalent beam method was then applied to determine the damage on buildings. The parameters describing the ground behavior and the building response were considered as uncertain. Additionally, the measurement and model errors were taken into account. An extension of the equivalent beam method was used to analyze buildings, which are not transverse to the tunnel axis.

A novel method for determining allowable settlements was presented (Sec. 3), which is a more systematic reliability-based approach with an explicit rationale than the deterministic methodology typically used in practice. Allowable settlements were defined as a settlement for which the probability of damage to the building is acceptably low. The allowable settlement differs for different positions of the tunnel heading: they are stricter if the TBM is approaching the building and the settlement is not fully developed and they increase after the tunnel face passes the location of the building. The proposed reliability-based approach additionally allows incorporating measurements made during the construction for updating the prediction of ground behavior and for updating the allowable settlements.

The proposed procedure was demonstrated on a case study of a tunnel construction in Barcelona (Sec. 4). The input values were selected based on the real documentation of the project and the results show a good agreement with the observed settlements and damages during the construction. A parametric study has shown the influence of the different model parameters on the resulting predictions. It was shown that the effect of the assumptions made in the probabilistic model have limited effect on the resulting allowable settlements.

\section{Acknowledgements}

The Spanish Ministry of Economy and Competitiveness (MINECO) and the ERDF (European Regional Development Funds) have funded this research in the framework of the SUBTIS project ('Study of the Sensitivity of Urban Tunnels to Tunneling Induced Settlements' - BIA2009-13233) by means of a pre-doctoral scholarship (FPI - BES-2010-030132). The authors want to thank the cooperation of Infrastructures.cat (before Gestió d'Infraestructures S.A. GISA), the public company responsible for the design and construction of the L9 Metro Line in Barcelona. 


\section{REFERENCES}

Attewell, P. B. and Woodman, J. P. (1982) Predicting the dynamics of ground settlement and its derivatives caused by tunnelling in soil. Ground Engineering, 15 (7), 13-22 and 36.

Attewell, P.B., Yeates, J. and Selby, A.R. (1986) Soil movements induced by tunneling and their effects on pipelines and structures. Blackie Academic and Professional, Glasgow

Boscardin, M.D. and Cording, E.J. (1989) Building response to excavation-induced settlement. Journal of Geotechnical Engineering, ASCE , 115(1), 1-21

Burland. J.B. (2008) The assessment of the risk of damage to buildings due to tunnelling and excavations. Jornada Técnica Payma Cotas: Movimiento de edificios inducidos por excavaciones. pp. 3.

Burland, J.B., Broms, B. and De Mello,V.F.B. (1977) Behaviour of foundations and structures. Proc. 9th International Conference on Soil Mechanics and Foundations Eng., 2, 495-546.

Burland, J.B. and Wroth, C.P., (1974). Settlement of buildings and associated damage. London: Pentech Press.

Camós, C., Molins, C. and Arnau, O. (2014). A case study of damage on masonry buildings produced by tunneling induced settlements. International Journal of Architectural Heritage, 8, 602-625.

Camós, C. and Molins, C. (2015) 3D analytical prediction of building damage due to ground subsidence produced by tunneling. Tunn. Undergr. Space Technol., Vol. 50, August 2015, 424-437, http://dx.doi.org/10.1016/j.tust.2015.08.012.

Camós, C., Špačková, O., Straub, D. and Molins, C. (2013) Development of a probabilistic model for the prediction of building damage due to tunneling induced settlements. 4th International Symposium on Geotechnical Safety and Risk. The Hong Kong University of Science and Technology, Hong Kong (China). Eds. L.M. Zhang, Y. Wang, G. Wang and D.Q. Li, Taylor and Francis Group.

Der Kiureghian, A. (2005). First- and second-order reliability methods. Engineering design reliability handbook. E. Nikolaidis, D. M. Ghiocel and S. Singhal. Boca Raton, FL., CRC Press.

Deulofeu, C., Schwarz, H., Maidl, U., and Comulada, M. (2007) Data management for highly mechanized shield tunneling in the construction of the L9 metro BCN. In Underground space- the $4^{\text {th }}$ dimension of metropolises, eds. Barták, Hrdina, Romancov and Zlámal. London, UK: Taylor and Francis Group.

Fargnoli, V., Boldini, D., Amorosi, A. (2013). TBM tunnelling-induced settlements in coarse-grained soils: The case of the new Milan underground line 5. Tunnelling and Underground Space Technology 38: $336-347$

Gong, W., Luo, Z., Juang, C. H., Huang, H., Zhang, J., Wang, L. (2014) Optimization of site exploration program for improved prediction of tunneling-induced ground settlement in clays. Computers and Geotechnics 56 (2014) 69-79

Melchers, R. E. (1999). Structural reliability analysis and prediction, 2nd Ed., John Wiley, Chichester; New York.

Nomoto, T., Mori, H., Matsumoto, M., 1995. Overview on ground movements during shield tunnellinga survey on Japanese shield tunnelling. In: Proc. Int. Symposium on Geotechnical Aspects of Underground Construction in Soft Ground, Balkema, pp. 345-35

O'Reilly, M. P. and New, M. 1982. Settlements above tunnels in the United Kingdom-Their magnitude and prediction. In Proceedings of Tunnelling '82. London, UK: Institution of Mining and Metallurgy, $173-181$.

Peck, R.B. (1969) Deep excavations and tunneling in soft ground. SOA Report, 7th Int. Conf. SMandFE.

Papaioannou, I. and Straub. D (2012). Reliability updating in geotechnical engineering including spatial variability of soil. Computers and Geotechnics 42: 44-51

Straub, D. (2011) Reliability updating with equality information. Probabilistic Engineering Mechanics 26: 254-258

Straub D., and Papaioannou I. (2014) Bayesian Updating with Structural Reliability Methods. J. Eng. Mech., 141(3), 04014134. http://dx.doi.org/10.1061/(ASCE)EM.1943-7889.0000839 
Skempton, A.W. and MacDonald, D.H. (1956) The allowable settlements of buildings. ICE Proceedings: Engineering Divisions, $727-768$

TYPSA. (2003) Análisis de los movimientos del terreno producidos por la excavación mecánica del túnel de la L9 en la zona de Santa Coloma de Gramanet ("Analsys of ground movements produced by mechanical excavation of the L9 tunnel in Santa Coloma de Gramanet'). Construction project of the L9 Metro Line in Barcelona. Bon Pastor - Can Zam. Stations and Infrastructure. Annex 8.

Yoo, C., Kim, Y. (2003) A web-based tunneling-induced building utility damage assessment system: TURISK. Tunnelling and Underground Space Technology 18: 497-511. 


\section{Annex A. Maximum bending and shear strains due to deflection}

Based on the shape of the settlement trough obtained according to Sec. 2.1, the maximum deflection ratios $\Delta / l$ that are affecting the building are calculated; $l$ is the horizontal distance between two reference points and $\Delta$ is the relative deflection between these two points. This relative deflection is given by the difference between the settlement profile and the straight lines connecting the settlements at the building extremes and at the inflection points (see Figure A.1). Inflection points define the position of the profile curvature change: Upwards concavity is known as sagging deflection, whereas downwards concavity refers to hogging deflection.

The calculation of Eqs.(5)-(7) is performed separately for the zone of the building undergoing sagging deflection and for the zones undergoing hogging deflection. Since the field of settlements is described by Gaussian profiles, the number of inflection points located along the position of the building can be 0,1 or 2 , depending on its length $l_{\text {build }}$, distance from building reference point $\hat{A}$ to the origin of coordinates $d_{\text {orig }}$ (Figure 2) and alignment $\theta$ with respect to the tunnel axis. For this reason, the building might be subjected to the following cases (Camós and Molins, 2015):

a) The building is subjected only to sagging (short buildings located above the tunnel axis; no inflection points are located along the building).

b) The building is subjected only to hogging (buildings located far from the tunnel longitudinal axis; no inflection points are located along the building).

c) The building is subjected to sagging and hogging (building starts in the zone above the tunnel (sagging) and reaches the hogging deflection zone; 1 inflection point is located along the building).

d) The central part of the building is subjected to sagging and its laterals to hogging (2 inflection points are located along the building).

Therefore, the total length of the building $l_{\text {build }}$ can be decomposed in three parts: $l_{\text {hog }}$, $l_{h o g_{2}}$ and $l_{\text {sag }}$ (Figure A.2), so that three different deflection ratios can be defined: $\Delta_{\text {sag }} / l_{\text {sag }}$, $\Delta_{\text {hog }_{1}} / l_{\text {hog }_{1}}$ and $\Delta_{\text {hog }_{2}} / l_{\text {hog }_{2}}$.

Using the deflection ratios $\Delta / l$ for the respective deflection zone, the maximum bending $\left(\varepsilon_{b \max }\right)$ and shear $\left(\varepsilon_{d \max }\right)$ strains for the given zone are calculated as (Burland and Wroth, 1974):

$\varepsilon_{\text {bmax }}=\frac{\frac{\Delta}{l}}{\left(\frac{l}{12 t}+\frac{3 I}{2 a l H} \frac{E}{G}\right)}$

$\varepsilon_{d \max }=\frac{\frac{\Delta}{l}}{\left(1+\frac{H l^{2}}{18 I} \frac{G}{E}\right)}$

where $H$ is the beam height, $I$ is the inertia per unit length which is equal to $H^{3} / 12, t$ is the position of the neutral axis and $a$ is the location of the fiber where strains are calculated. In case of sagging deflection, the neutral axis is assumed to be at middle height $(t=H / 2)$. In case of 
hogging deflection, the neutral axis is assumed to be at the top fiber $(t=H)$. Strains are calculated in the most critical fiber from the position of the neutral axis, so that $a=t$ in both cases.

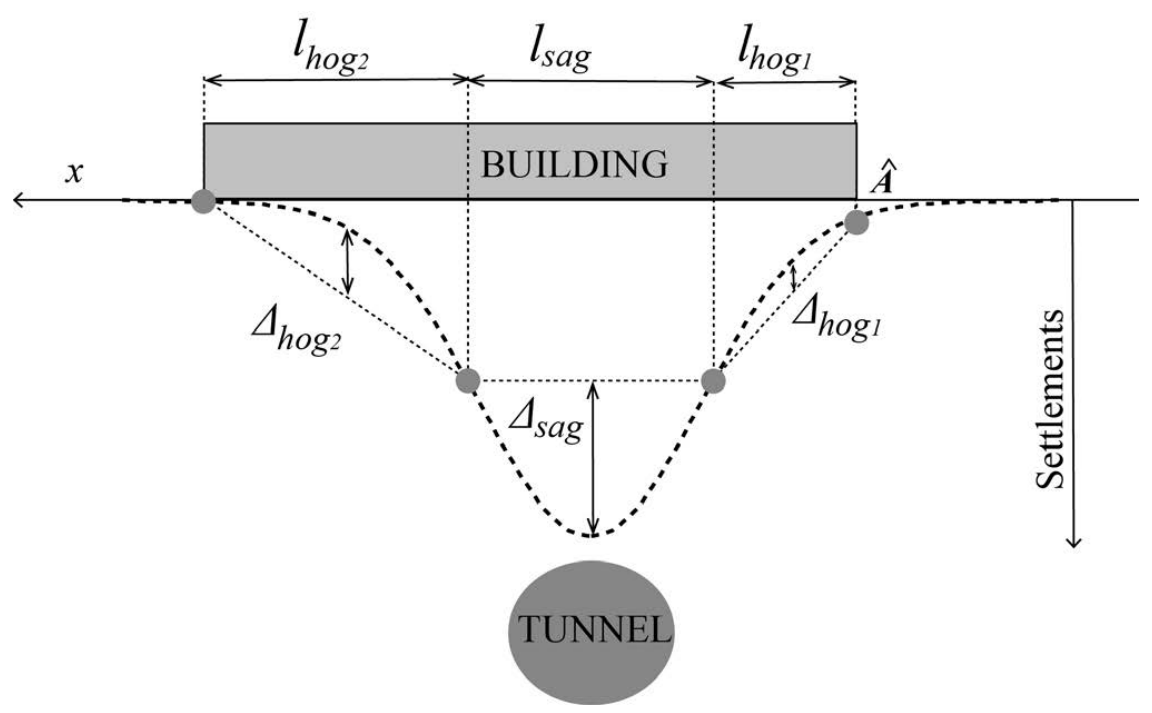

Figure A.1. Deflection ratios for sagging and hogging zones of the building.

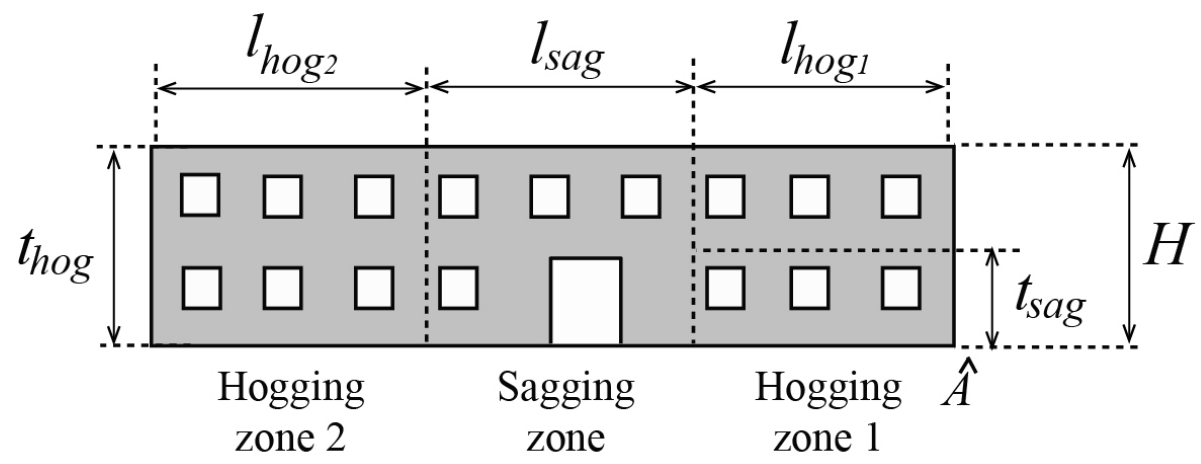

Figure A.2. Equivalent beam model - Building geometry

\section{Annex B. Ground horizontal strain}

Horizontal displacements in $[\mathrm{mm}]$ in the transverse $\left(U_{x}\right)$ and longitudinal $\left(U_{y}\right)$ directions with respect to the tunnel axis at a certain position with coordinates $x, y, z$ in [m] are given by (O’Reilly and New,1982):

$U_{x}=\frac{x}{z_{0}-z} \cdot S$

$U_{y}=1000 \cdot \frac{V_{L} \cdot d^{2}}{8 \cdot\left(z_{0}-z\right)}$. 


$$
\cdot\left[\exp \left(\frac{-\left(y-\left(y_{s}+y_{0}\right)\right)^{2}-x^{2}}{2 \cdot K_{y}^{2} \cdot\left(z_{0}-z\right)^{2}}\right)-\exp \left(\frac{-\left(y-\left(y_{f}\right)\right)^{2}-x^{2}}{2 \cdot K_{y}^{2} \cdot\left(z_{0}-z\right)^{2}}\right)\right]
$$

where $V_{L}$ is the unit volume loss, $d$ is the tunnel diameter, $z_{0}$ is the depth of tunnel axis, $K_{x}$ and $K_{y}$ are the trough width parameters of the Gaussian settlement profiles in the transverse and longitudinal directions respectively, $y_{s}$ represents the position of the tunnel face, $y_{f}$ determines the distance of the tunnel end location, $y_{0}$ is the horizontal shift of the longitudinal settlement profile with respect to the tunnel face defined in Eq. (3) and $S$ is given by Eq. (1).

The field of strains in both directions is given by:

$$
\begin{aligned}
\varepsilon_{h, x x}=\frac{\partial U_{x}}{\partial x}= & \frac{\frac{S}{1000}}{z_{0}-z} \cdot\left(1-\left(\frac{x^{2}}{K_{x}^{2} \cdot\left(z_{0}-z\right)^{2}}\right)\right) \\
\varepsilon_{h, y y}=\frac{\partial U_{y}}{\partial y}= & \\
\frac{V_{L} \cdot d^{2}}{8 \cdot\left(z_{0}-z\right)} \cdot[ & \left(\frac{-2 y+2\left(y_{s}+y_{0}\right)}{2 \cdot K_{y}^{2} \cdot\left(z_{0}-z\right)^{2}}\right) \cdot \exp \left(\frac{-\left(y-\left(y_{s}+y_{0}\right)\right)^{2}-x^{2}}{2 \cdot K_{y}^{2} \cdot\left(z_{0}-z\right)^{2}}\right) \\
& \left.-\left(\frac{-2 y+2\left(y_{f}\right)}{2 \cdot K_{y}^{2} \cdot\left(z_{0}-z\right)^{2}}\right) \cdot \exp \left(\frac{-\left(y-\left(y_{f}\right)\right)^{2}-x^{2}}{2 \cdot K_{y}^{2} \cdot\left(z_{0}-z\right)^{2}}\right)\right]
\end{aligned}
$$

and

$\varepsilon_{h, x y}=\frac{1}{2}\left(\frac{\partial U_{x}}{\partial y}+\frac{\partial U_{y}}{\partial x}\right)$

where

$$
\begin{aligned}
& \frac{\partial U_{x}}{\partial y}=\frac{x}{z_{0}-z} \cdot\left(-\frac{V_{L} \cdot \pi \cdot d^{2}}{\sqrt{2 \pi} \cdot K_{x} \cdot\left(z_{0}-z\right) \cdot 4}\right) . \\
& \cdot\left(\frac{1}{\sqrt{2 \pi}} e^{-\frac{\left(\frac{y-\left(y_{s}+y_{0}\right)}{K_{y} \cdot\left(z_{0}-z\right)}\right)^{2}}{2}} \cdot\left(\frac{1}{K_{y} \cdot\left(z_{0}-z\right)}\right)-\frac{1}{\sqrt{2 \pi}} e^{-\frac{\left(\frac{y-y_{f}}{K_{y} \cdot\left(z_{0}-z\right)}\right)^{2}}{2}} \cdot\left(\frac{1}{K_{y} \cdot\left(z_{0}-z\right)}\right)\right) . \\
& \cdot\left(\exp \left(-\frac{x^{2}}{2 \cdot K_{x}^{2} \cdot\left(z_{0}-z\right)^{2}}\right)\right)
\end{aligned}
$$




$$
\begin{aligned}
& \frac{\partial U_{y}}{\partial x}=\frac{V_{L} \cdot d^{2}}{8 \cdot\left(z_{0}-z\right)} . \\
& \cdot \frac{(-2 x)}{2 \cdot K_{y}^{2} \cdot\left(z_{0}-z\right)^{2}}\left[\exp \left(\frac{-\left(y-\left(y_{s}+y_{0}\right)\right)^{2}-x^{2}}{2 \cdot K_{y}^{2} \cdot\left(z_{0}-z\right)^{2}}\right)-\exp \left(\frac{-\left(y-\left(y_{f}\right)\right)^{2}-x^{2}}{2 \cdot K_{y}^{2} \cdot\left(z_{0}-z\right)^{2}}\right)\right]
\end{aligned}
$$

Determination of $\varepsilon_{h}$ in Eqs. (5)-(6) is also performed separately for the zones of the building undergoing sagging and hogging deflection. The nature of strain in sagging zones is compressive and therefore, they contribute favorably to damage reduction. A conservative approximation is taken considering null ground tensile strain in this part of the building, i.e. $\varepsilon_{h, s a g}=0$.

The nature of strains in hogging is tensile and they contribute to damage production. Therefore $\varepsilon_{h, h o g 1}$ and $\varepsilon_{h, h o g 2}$ are taken as the mean value of $\varepsilon_{h}$ given by Eq. (7) along the respective hogging length.

\section{Annex C. Maximum bending and shear strains due to deflection}

$b$

$c$

c.o.v.

$d$

$d_{\text {orig }}$

$E / G$

$E_{\varepsilon_{b r}}$

$E_{\varepsilon_{d r}}$

$E_{b r}^{h o g, 1}$

$E_{b r}^{h o g, 2}$

$E_{b r}^{s a g}$

$E_{d r}^{h o g, 1}$

$E_{d r}^{h o g, 2}$

$E_{d r}^{s a g}$

$E_{E}$

$E_{f}$

$E_{m}$

$F_{\varepsilon_{\text {lim }}}$

$f_{E}$

H

I

$i_{x}$ (or $\left.i\right)$

$i_{y}$

Height of the equivalent beam fiber where strains are calculated

Distance between two locations within a quasi-homogeneous section

Scaling constant

Coefficient of variation

Tunnel diameter

Distance from origin of coordinates to building reference point $\hat{A}$

Material elastic / shear modulus ratio

Error of resultant extreme fiber strain in bending, accounting for ground strain

Error of resultant extreme fiber strain in shear, accounting for ground strain

Error of maximum bending strain in hogging zone 1

Error of maximum bending strain in hogging zone 2

Error of maximum bending strain in sagging zone

Error of maximum shear strain in hogging zone 1

Error of maximum shear strain in hogging zone 2

Error of maximum shear strain in sagging zone

Error including the ground model error and the settlement measurement error

Ground model error for settlement prediction

Settlement measurement error

Failure of the construction process producing intolerable damage

Probability density function of $E_{E}$

Building height

Inertia per unit length of the equivalent beam

Location of inflection point in the transverse direction to tunnel axis

Location of inflection point in the longitudinal direction to tunnel axis 


\begin{tabular}{|c|c|}
\hline$k$ & Realization of trough width parameter \\
\hline$k_{i}$ & Trough width parameter at location of measurement $s_{i}$ \\
\hline$k_{m}$ & Trough width parameter at location of measurement $s_{m}$ \\
\hline$K_{x}($ or $K)$ & Trough width parameter in the transverse direction to tunnel axis \\
\hline$K_{y}$ & Trough width parameter in the longitudinal direction to tunnel axis \\
\hline$l$ & Horizontal distance between two reference points \\
\hline$l_{\text {build }}$ & Building length \\
\hline$l_{\text {hog }_{1}}$ & Building length in hogging zone 1 \\
\hline$l_{\text {hog }_{2}}$ & Building length in hogging zone 2 \\
\hline$l_{\text {sag }}$ & Building length in sagging zone \\
\hline$L_{i}$ & Likelihood function \\
\hline $\operatorname{Pr}(F)$ & Probability of failure \\
\hline$p_{T}$ & Probability of intolerable damage \\
\hline$R_{K}$ & Constant autocorrelation function for variable $K$ \\
\hline$R_{V_{L}}$ & Constant autocorrelation function for variable $V_{L}$ \\
\hline$S$ & Settlement \\
\hline $\boldsymbol{S}$ & Vector of settlement measurements \\
\hline$s_{i}$ & Value of $i$-th settlement measurement \\
\hline$s_{\text {lim }}$ & Allowable value of settlement \\
\hline$s_{\text {lim }}^{*}$ & Updated allowable value of settlement \\
\hline$s_{m}$ & Realization of settlement measurement \\
\hline$S_{m}$ & Settlement measurement \\
\hline$S_{\max }$ & Maximal settlement \\
\hline$t$ & Position of neutral axis in the equivalent beam \\
\hline$t_{\text {hog }}$ & Position of neutral axis in the hogging zone of the equivalent beam \\
\hline$t_{s a g}$ & Position of neutral axis in the sagging zone of the equivalent beam \\
\hline$u$ & Realization of normal standard variable \\
\hline$u_{i}$ & Realization of normal standard variable at location of measurement $s_{i}$ \\
\hline$U_{x}$ & Ground horizontal movements in the transverse direction (to tunnel axis) \\
\hline$U_{y}$ & Ground horizontal movements in the longitudinal direction (to tunnel axis) \\
\hline$v_{L_{i}}$ & Volume loss at location of measurement $s_{i}$ \\
\hline$v_{L_{m}}$ & Volume loss at location of measurement $s_{m}$ \\
\hline$V_{L}$ & Ground volume loss \\
\hline$v_{L}$ & Realization of ground volume loss \\
\hline $\mathbf{X}$ & Vector of random variables \\
\hline$x$ & $x$-coordinate \\
\hline$x_{i}$ & $x$-coordinate of measurement $s_{i}$ \\
\hline$x_{m}$ & $x$-coordinate of measurement $s_{m}$ \\
\hline$y$ & $y$-coordinate \\
\hline$y_{s_{i}}$ & Location of tunnel face when measurement $s_{i}$ is taken \\
\hline$y_{s_{m}}$ & Location of tunnel face when measurement $s_{m}$ is taken \\
\hline$y_{0}$ & Horizontal shift of longitudinal settlement profile \\
\hline$y_{f}$ & Location of tunnel origin \\
\hline$y_{i}$ & $y$-coordinate of measurement $s_{i}$ \\
\hline
\end{tabular}




\begin{tabular}{|c|c|}
\hline$y_{m}$ & $y$-coordinate of measurement $s_{m}$ \\
\hline$y_{s}$ & Location of tunnel face \\
\hline$z$ & $z$-coordinate \\
\hline$z_{0}$ & Depth of tunnel axis \\
\hline$z_{i}$ & Depth of measurement $s_{i}$ \\
\hline$z_{m}$ & Depth of measurement $s_{m}$ \\
\hline$\Delta$ & Relative deflection between two reference points \\
\hline$\Delta / l$ & Deflection ratio \\
\hline$\Delta_{s a g} / l_{\text {sag }}$ & Deflection ratio in sagging zone \\
\hline$\Delta_{\text {hog }_{1}} / l_{\text {hog }_{1}}$ & Deflection ratio in hogging zone 1 \\
\hline$\Delta_{\text {hog }_{2}} / l_{\text {hog }_{2}}$ & Deflection ratio in hogging zone 2 \\
\hline$\delta$ & $\begin{array}{l}\text { Ratio between surface settlement above tunnel face and maximal settlement at } \\
\text { infinite distance of the face }\end{array}$ \\
\hline$\varepsilon_{\text {bmax }}$ & Maximum tensile strain in the equivalent beam due to bending \\
\hline$\varepsilon_{b r}^{h o g, 1}$ & Maximum bending strain in hogging zone 1 \\
\hline$\varepsilon_{b r}^{\text {hog, } 2}$ & Maximum bending strain in hogging zone 2 \\
\hline$\varepsilon_{b r}^{s a g}$ & Maximum bending strain in sagging zone \\
\hline$\varepsilon_{b r}$ & Resultant extreme fiber strain in bending, accounting for ground strain \\
\hline$\varepsilon_{d \max }$ & Maximum tensile strain in the equivalent beam due to shear \\
\hline$\varepsilon_{d r}^{h o g, 1}$ & Maximum shear strain in hogging zone 1 \\
\hline$\varepsilon_{d r}^{\text {hog, } 2}$ & Maximum shear strain in hogging zone 2 \\
\hline$\varepsilon_{d r}^{s a g}$ & Maximum shear strain in sagging zone \\
\hline$\varepsilon_{d r}$ & Resultant extreme fiber strain in shear, accounting for ground strain \\
\hline$\varepsilon_{h, h o g_{1}}$ & Resultant horizontal ground strain at surface in hogging zone 1 \\
\hline$\varepsilon_{h, h o g_{2}}$ & Resultant horizontal ground strain at surface in hogging zone 2 \\
\hline$\varepsilon_{h, s a g}$ & Resultant horizontal ground strain at surface in sagging zone \\
\hline$\varepsilon_{h}$ & Resultant horizontal ground strain \\
\hline$\varepsilon_{\text {lim }}$ & Limit strain value for damage classification \\
\hline$\varepsilon_{\max }$ & Maximum strain in the equivalent beam \\
\hline$\varepsilon_{h, x x}$ & Component $x x$ of ground strain infinitesimal tensor \\
\hline$\hat{\varepsilon}_{h, \widehat{x x}}$ & Component $\widehat{x x}$ of ground strain infinitesimal tensor \\
\hline$\varepsilon_{h, x y}$ & Component $x y$ of ground strain infinitesimal tensor \\
\hline$\varepsilon_{h, y y}$ & Component $y y$ of ground strain infinitesimal tensor \\
\hline$\theta$ & Building alignment respect to $x$ axis \\
\hline$\mu_{V_{L}}$ & Lognormal parameter of $V_{L}$ \\
\hline$\mu_{V_{L}}^{\prime}$ & Modified lognormal parameter of $V_{L}$ \\
\hline$\mu_{K}$ & Lognormal parameter of $K$ \\
\hline$\mu_{K}^{\prime}$ & Modified lognormal parameter of $K$ \\
\hline$\rho_{K}$ & Correlation coefficient of $K$ \\
\hline$\rho_{V_{L}}$ & Correlation coefficient of $V_{L}$ \\
\hline$\sigma_{E_{E}}$ & Standard normal deviation of $E_{E}$ \\
\hline$\sigma_{V_{L}}$ & Lognormal parameter of $V_{L}$ \\
\hline
\end{tabular}


$\sigma_{V_{L}}^{\prime} \quad$ Modified lognormal parameter of $V_{L}$

$\sigma_{K} \quad$ Lognormal parameter of $K$

$\sigma_{K}^{\prime} \quad$ Modified lognormal parameter of $K$

$\Phi(\cdot) \quad$ Cumulative standard normal distribution function

$\Omega_{0} \quad$ Observation domain

$\Omega_{F} \quad$ Failure domain

$\Omega_{i} \quad$ Corresponding observation domain for measurement $s_{i}$ 